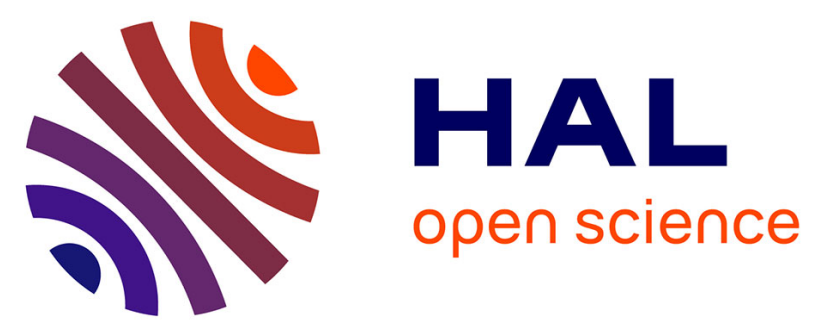

\title{
A mechanistic rationale approach revealed the unexpected chemoselectivity of an artificial Ru-dependent oxidase: a dual experimental/theoretical approach
}

Sarah Lopez, David Michael Mayes, Serge Crouzy, Christine Cavazza, Chloé Leprêtre, Yohann Moreau, Nicolai Burzlaff, Caroline Marchi-Delapierre, Stéphane Ménage

\section{- To cite this version:}

Sarah Lopez, David Michael Mayes, Serge Crouzy, Christine Cavazza, Chloé Leprêtre, et al.. A mechanistic rationale approach revealed the unexpected chemoselectivity of an artificial Ru-dependent oxidase: a dual experimental/theoretical approach. ACS Catalysis, 2020, 10 (10), pp.5631-5645. 10.1021/acscatal.9b04904 . hal-02865406

\author{
HAL Id: hal-02865406 \\ https://hal.science/hal-02865406
}

Submitted on 26 Nov 2020

HAL is a multi-disciplinary open access archive for the deposit and dissemination of scientific research documents, whether they are published or not. The documents may come from teaching and research institutions in France or abroad, or from public or private research centers.
L'archive ouverte pluridisciplinaire HAL, est destinée au dépôt et à la diffusion de documents scientifiques de niveau recherche, publiés ou non, émanant des établissements d'enseignement et de recherche français ou étrangers, des laboratoires publics ou privés. 


\section{A Mechanistic Rationale Approach Revealed the Unexpected Chemoselectivity of an Artificial Ru-dependent Oxidase - A Dual Experimental/Theoretical Approach}

By Sarah Lopez, ${ }^{1,2}$ David Michael Mayes, ${ }^{1}$ Serge Crouzy, ${ }^{1}$ Christine Cavazza, ${ }^{1}$ Chloé Leprêtre, ${ }^{1}$ Yohann Moreau, ${ }^{1}$ Nicolai Burzlaff, ${ }^{3}$ Caroline Marchi-Delapierre*1 and Stéphane Ménage ${ }^{1}$

[1] Univ. Grenoble Alpes, CEA, CNRS, IRIG, CBM, F-38000 Grenoble, France. [2] Univ. Grenoble-Alpes, DCM-SeRCO, Grenoble, France. [3] Department of Chemistry and Pharmacy, Friedrich-AlexanderUniversity of Erlangen-Nürnberg, Egerlandstraße 1, 91058 Erlangen, Germany.

Caroline.marchi-delapierre@cea.fr

\section{Abstract}

Artificial enzymes represent an attractive alternative to design abiotic biocatalysis. EcNikA-Ru1, an artificial metalloenzyme developed by embedding a ruthenium-based catalyst into the cavity of the periplasmic nickel-binding protein NikA, was found to efficiently and selectively transform certain alkenes. The objective of this study was to provide a rationale on the enzymatic function and the unexpected substrate-dependent chemoselectivity of EcNikA-Ru1 thanks to a dual experimental/computational study.

We observed that the de novo active site allows the formation of the terminal oxidant via the formation of a ruthenium aquo species that subsequently reacts with the hypervalent iodine of phenyl iodide diacetic acid. The oxidation process relies on a $\mathrm{Ru}^{\mathrm{IV}}=\mathrm{O}$ pathway via a two-step reaction with a radical intermediate, resulting in the formation of either a chlorohydrin or an epoxide.

The results emphasize the impact of the protein scaffold on the kinetics of the reaction, through i) the promotion of the starting oxidizing species via the exchange of a CO ligand with a water molecule; and ii) the control of the substrate orientation on the intermediate structures, formed after the $\mathrm{Ru}^{\mathrm{IV}}=0$ attack. When a $C \alpha$ attack is preferred, chlorohydrins are formed while an attack on $C \beta$ leads to an epoxide.

This work provides an evidence that artificial enzymes mimic the behavior of their natural counterparts.

\section{Keywords}

Artificial enzymes - catalysis - oxidation - hydroxychlorination - epoxidation - computational chemistry - reaction paths - spin flip 


\section{Introduction}

In the search to improve the sustainability of organic chemistry, new green catalytic approaches are targeted. ${ }^{1}$ When designing novel processes based around a metal-containing catalyst, the following features are desirable: abundant metal(s), easy-to-handle ligands, safe reactants/solvents, and minimal reaction steps (e.g. cascade reactions). Artificial enzymes (ArMs), based on the insertion of an inorganic catalyst as an active site into an unreactive protein scaffold, provide a promising alternative to purely biological catalysts by allowing the design of unnatural reactions. ${ }^{2}$ While the catalytic efficiency of natural enzymes can be optimized by mutagenesis, ${ }^{3}$ ArMs offer an additional degree of freedom through the chemical modification of the inorganic catalyst. Because the active site of an ArM is formed by combining a protein environment with a stable inorganic complex, the catalytic properties of both the protein and the inorganic complex can be investigated separately, simplifying the process by which the resulting ArM can be optimized.

The flexibility in design afforded by ArMs allows reaction pathways to be controlled, and means that the repertoire of possible transformations can be expanded to unnatural reactions.

Our group has designed a Ru-based ArM by embedding a ruthenium complex (Ru1) (Figure 1) in the binding pocket of the nickel-binding protein NikA from Escherichia coli (EcNikA) to form the EcNikARu1 hybrid. ${ }^{4}$

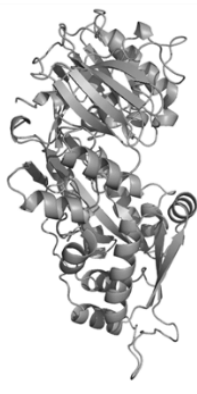

EcNikA

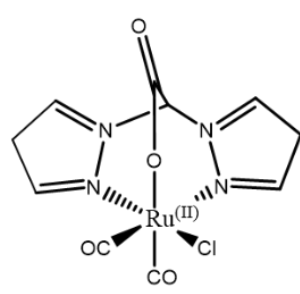

Ru1

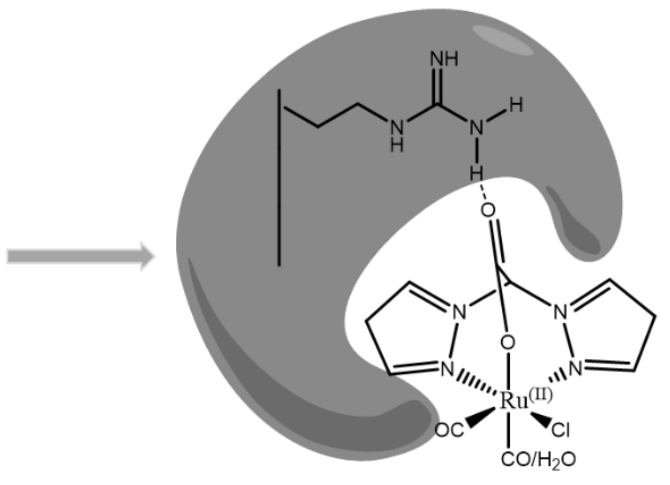

EcNikA-Ru1/2

Figure 1. Drawings of EcNikA, Ru1 and EcNikA-Ru1/2. Arg137 is included in EcNikA-Ru1/2 to show the salt bridge stabilizing the complex inside the protein.

EcNikA-Ru1 was shown to react with alkenes to give the corresponding $\beta$-chloro- $\alpha$-hydroxy adducts. The understanding of the reaction mechanism at the molecular level is of great importance for the optimization of this kind of ArM. In particular, the nature of the oxidizing species and its impact on the reaction (enantio-, chemo-, and regioselectivity) must be determined to allow a better optimization strategy. Here, we propose a reaction mechanism that has been formulated using a combination of theoretical and experimental data. In particular, we focused on deciphering the overall mechanism 
between the starting Ru1 complex and the oxidant, revealing the transient formation of a genuine complex-oxidant adduct. Density functional theory (DFT) calculations confirmed the importance of the protein scaffold on the complex activation, giving a new example of the advantageous use of artificial enzymes. Moreover, the unexpected reaction chemoselectivity (epoxidation vs hydroxychlorination) is related to the competition between kinetic and thermodynamic control of the reaction. This reaction pathway is dependent on the substrate orientation in the computed radical intermediates, which is driven by the protein environment. Interestingly, the modeled formation of the $\beta$-chlorohydrins involves a chlorine transfer that is reminiscent to the one observed in iron chloroperoxidase catalyzing the formation of (di)chlorinated compounds. ${ }^{5}$

\section{RESULTS}

\section{Catalytic studies}

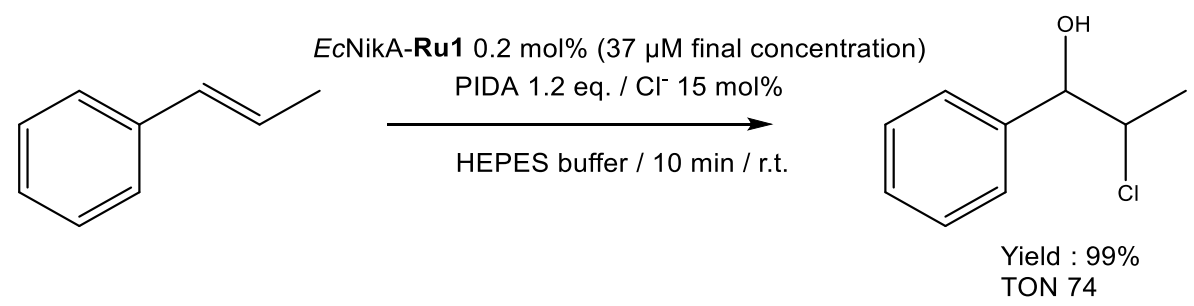

Scheme 1. Standard oxidation conditions for BMS.

In a previous study, EcNikA-Ru1 was shown to react with alkenes in the experimental conditions given by scheme $1 .{ }^{4}$ Typically, optimum catalytic efficiency was obtained using a 1/500/600/75 ratio for catalyst/substrate/oxidant/chloride, respectively, for a $37 \mu \mathrm{M}$ final concentration of either Ru1 or EcNikA-Ru1 for a 10 minutes reaction time at room temperature. Substrates were solubilized in acetonitrile prior mixing to the buffered medium but PIDA was added as a solid. The complex Ru1 alone was inert, suggesting the activation of the catalyst via its binding to the protein scaffold. ${ }^{4}$ The hydroxychlorination of trans- $\beta$-methylstyrene (BMS) in the presence of $\mathrm{Phl}(\mathrm{OAC})_{2}$ (PIDA) was performed with a complete regioselectivity to give the $\beta$-chloro- $\alpha$-hydroxy adduct (Table S1) with a yield of $99 \%$ with respect to chloride that is the limiting reactant ( $15 \%$ with respect to substrate). The catalyzed hydroxychlorination had a turn over number (TON) of 74 and a turn over frequency (TOF) of $7 \mathrm{~min}^{-1}$, which is highly efficient compared to similar systems, ${ }^{6}$ whereas apo-EcNikA is inactive. Likewise, an EcNikA-Ru(DMSO) ${ }_{2} \mathrm{Cl}_{2}$ analogue was found to be unreactive.

Then, the reactivity of ECNikA-Ru1 and Ru1 was investigated for the oxidation of 4-methoxystyrene (MOS) under the conditions previously described for BMS (Scheme 2, Table S1). First, no product was detected by GC-MS either in the absence of the catalyst or in the presence of EcNikA alone. Second, 
Ru1 was found quasi inactive under these conditions. Product analysis revealed the exclusive formation of the unexpected 2-(4-methoxyphenyl)oxirane with a maximum yield of $35 \%$ after 10 minutes. EcNikA-Ru1 epoxidation was highly efficient, with a TON of 175 in 10 minutes, giving a TOF of $18 \mathrm{~min}^{-1}$. No side product was observed. These values are unmatched when compared to those of the Ru1 even in organic solvent (26 TON and TOF of $\left.0.02 \mathrm{~min}^{-1}\right),{ }^{7}$ or to the ones of the artificial streptavidin- $\mathrm{OsO}_{4}$ (27 TON with an estimated TOF around $0.02 \mathrm{~min}^{-1}$ but for diol formation), ${ }^{6}$ highlighting the ability of EcNikA to speed-up reactions.

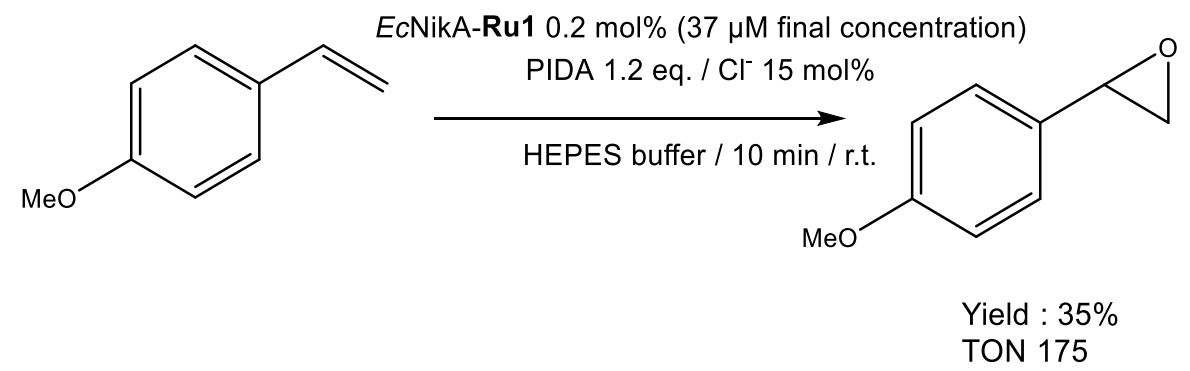

Scheme 2. Standard oxidation conditions for MOS.

The question of the starting active species then arose. Previously, we showed that the crystal structures of EcNikA-Ru1 and Ru1 displayed significant structural differences in ruthenium complex geometry (Figure 2). The major disparities are the elongation of the Ru- $t C O$ length from 1.9 to $2.3 \AA$ in EcNikA-Ru1 compared with Ru1, and the change of the Ru-tCO angle from $180^{\circ}$ in Ru1 to $118^{\circ}$ in EcNikA-Ru1. ${ }^{4}$ The metrics of the $t \mathrm{CO}$ are related to its loose binding to the ruthenium ion, as observed previously on iron systems. ${ }^{8}$ We also observed that, depending on the $x$-ray structures, the electron density for this region cannot be systematically modelled as a CO ligand. Here, the x-ray structure of EcNikA-Ru2 was solved at $1.9 \AA$ A by soaking EcNikA-FeEDTA crystals with Ru1 (PDB code: 6R4Q, Figure 2, Table S2). As observed previously, two molecules were present in the asymmetric unit, one of which contained the ruthenium complex at the NikA binding site with an occupancy of approximately 0.9. Only this molecule containing the ruthenium complex will be discussed hereafter. Compared to the crystal structure of EcNikA-Ru1, the major difference is the absence of the electron density corresponding to $t \mathrm{CO}$. As expected, the loose binding of $t \mathrm{CO}$ to Ru1 led to its release over time. In its place, a weak electron density rather corresponding to a monoatomic species was observed, which could not be clearly modelled. However, based on the fact that Ru(II) prefers a six-coordinate geometry, this electron density was modelled as a water molecule with a Ru- $\mathrm{H}_{2} \mathrm{O}$ distance of $1.9 \AA$, in agreement with literature and an occupancy of 0.9, forming EcNikA-Ru2. Embedding Ru1 into NikA led to the build-up of catalytic activity, pushing us to correlate the Ru2 formation with the ArM reactivity. 

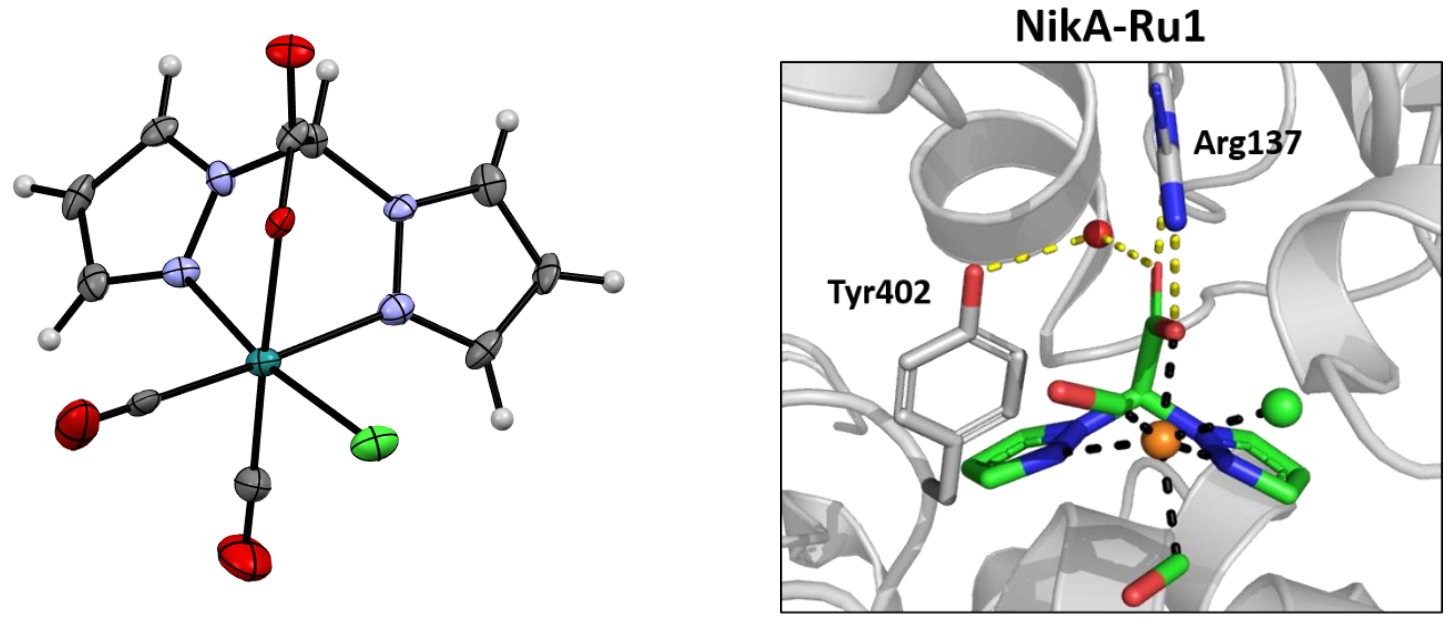

NikA-Ru2

\begin{tabular}{|c|c|c|c|c|}
\hline & $\begin{array}{c}\text { Ru-O } \\
(\AA)\end{array}$ & $\begin{array}{c}\text { Ru-Cl } \\
(\AA)\end{array}$ & $\begin{array}{c}\text { Ru- } \\
t \text { (CO } \\
(\AA)\end{array}$ & $\begin{array}{c}\text { Ru- } \\
\mathbf{O H}_{2} \\
(\AA)\end{array}$ \\
\hline Ru1 & 2.11 & 2.37 & 1.88 & - \\
\hline $\begin{array}{c}\text { EcNikA- } \\
\text { Ru1 }\end{array}$ & 2.2 & 2.5 & 2.3 & - \\
\hline $\begin{array}{c}\text { EcNikA- } \\
\text { Ru2 }\end{array}$ & 2.2 & 2.5 & - & 1.9 \\
\hline
\end{tabular}

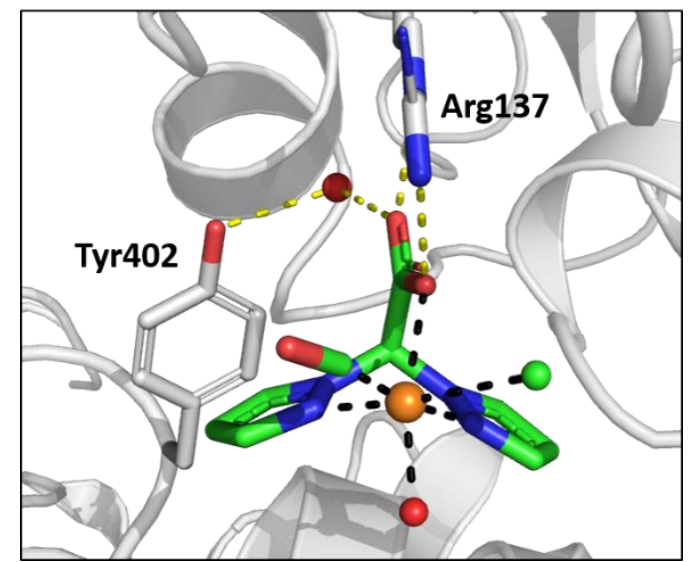

Figure 2. Structures of Ru1 (CCDC : fsbu18) (top left), EcNikA-Ru1 (PDB code: 5L8D) (top right) and EcNikA-Ru2 (PDB code: 6R4Q) (bottom). In protein: $\mathrm{Ru}$ is depicted as an orange sphere, $\mathrm{Cl}$ as a green sphere and water molecules as red spheres. The ruthenium ligand and $\mathrm{CO}$ are in sticks. The figures were prepared with PyMOL (The PyMOL molecular graphic system, Version 2.0 Schrödinger, LCC).

The speciation in solution between Ru1 and Ru2 was also investigated using IR spectroscopy. As published previously, the IR spectrum of EcNikA-Ru1 displayed three resonances at $2082 \mathrm{~cm}^{-1}, 2017$ $\mathrm{cm}^{-1}$ and $2005 \mathrm{~cm}^{-1}{ }^{4}$ The 2082 and 2005 resonances were also observed in the spectrum of Ru1 in solution, suggesting that free Ru1 was present in addition to a new species. The $v \mathrm{CO}$ were calculated by DFT with B3LYP functional, ${ }^{9}$ a def2-SVP split valence polarization basis set $^{10}$ and a Polarizable Continuum Model (PCM) for the solvent (Table S3) leading to two vibrations at higher energies (2150 and $2078 \mathrm{~cm}^{-1}$ ); the differences between the two resonances were similar when comparing the observed and calculated data $\left(\Delta \mathrm{E}=72 \mathrm{vs} 77 \mathrm{~cm}^{-1}\right)$. The impact of the protein on these vibrations was calculated, taking into account the already identified protein residues impacting the complex 
stability. ${ }^{11}$ Results showed that the $v$ CO were slightly affected (in a $5 \mathrm{~cm}^{-1}$ range), suggesting that the third vibration observed at $2017 \mathrm{~cm}^{-1}$ was issued from a distinct species, likely a mono CO species. Calculated Ru2 vibration frequencies were found significantly lower than those of Ru1 and similar to the observed one $\left(2050 \mathrm{~cm}^{-1}\right.$ vs $\left.2017 \mathrm{~cm}^{-1}\right)$.

Taken all together, we assume that the major species in solution is EcNikA-Ru2. The mono-CO resonance at $2017 \mathrm{~cm}^{-1}$ was not observed in the unbound Ru1, which is instead more likely to lose the chloride ligand (as shown by electrospray ionization/mass spectrometry studies), suggesting that the stabilization of this chloride group could also play a role in the activity of EcNikA-Ru1. ${ }^{4}$

\section{Reaction mechanism studies}

EcNikA-Ru2 catalyzed the epoxidation of MOS in aqueous medium, whereas a chlorohydrin is formed with BMS. The hypervalent iodine compound PIDA was found to be the most effective stoichiometric oxidant to catalyze both the epoxidation of MOS and the hydroxychlorination of BMS (Table S4). This discrepancy in chemoselectivity led us to decipher the reaction mechanism using calculation based on experimental evidence.

\section{Experimental studies}

The activation of PIDA is essential for catalysis. The reaction steps for the alkene oxidation may follow several different pathways, distinguished by the involvement of metal-centered redox processes. Firstly, a transient amino acid-based oxidation may occur. Secondly, the protein scaffold or the metal complex may activate PIDA by its binding through a Lewis acid interaction with either an amino acid residue or the metal. ${ }^{12}$ Finally, the metal center may activate the oxidant via a redox process. In the following, we describe each possibility and confronted them to our experimental data.

Control reactions have been run with the open form of the protein apo EcNikA (Table S1). As only a poor reactivity was observed, it seems that it is not an amino acid that is responsible of catalytic activity.

This was confirmed by a metal complex exchange strategy while keeping the closed form of the protein structure and the size of the cavity. Since EcNikA is able to bind metal EDTA derivatives, ${ }^{13}$ an EcNikAMg(EDTA) hybrid was synthesized in situ. ${ }^{14}$ The absence of reactivity for both chlorohydrin and epoxide formation (Table S1) confirmed the absence of amino acid based of Lewis acid pathway. Moreover, the possible aspecific binding of a free ruthenium atom issued from Ru1 decomposition to the protein was also ruled out by the absence of reactivity of the mixture $E c$ NikA and $\mathbf{R u}(\mathrm{DMSO})_{2} \mathrm{Cl}_{\mathbf{2}}$ (Table S1). While confirming that the Ru complex controlled the reaction, we could not discriminate between a 
metal Lewis acid and a metal based redox mechanisms. Unfortunatly, any attemps to synthesize a $\mathrm{Mg}$ analog of Ru1 was unsuccessful, because a $\mathrm{Mg}(\mathrm{bpza})_{2}$ complex was the most stable species in solution.

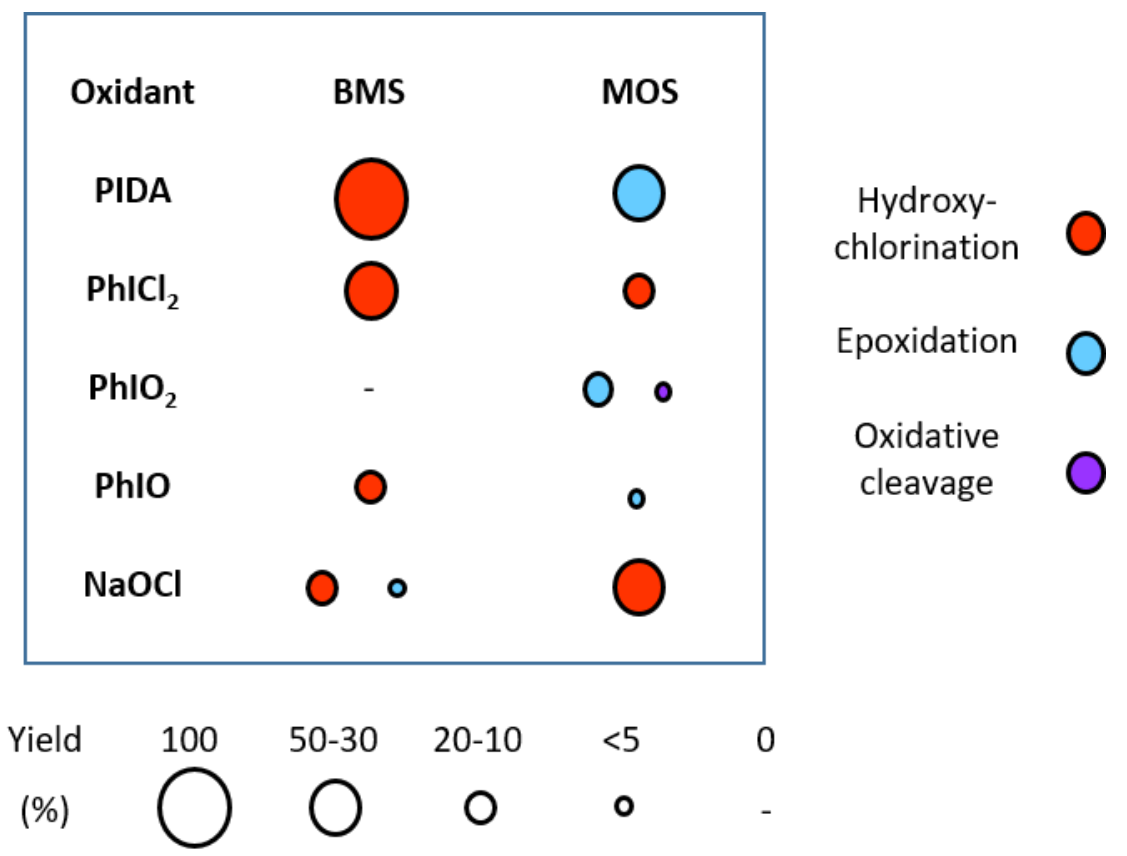

Figure 3. Oxidation reaction with different oxidants. Reaction conditions: Standard conditions: $1 / 500 / 600 / 75$ ratio for catalyst/substrate/oxidant/chloride, respectively, for a final EcNikA-Ru1 concentration of $37 \mu \mathrm{M}$ in $40 \mathrm{mM}$ Tris. $\mathrm{HCl} \mathrm{pH} 7.5$ and $10 \mathrm{mM}$ HEPES pH 7.0 ; reaction at room temperature for $10 \mathrm{~min}$.

The $73 \%$ diastereomeric excess, observed for the BMS $\beta$-chloro- $\alpha$-hydroxychlorohydrin production (Table S1), is suggestive of a stepwise reaction involving the formation of an intermediate. In the case of MOS, the ring closing of the chlorohydrin issued from a putative hydroxychlorination was not considered since the chlorohydrin, made separately, was unreactive in our standard conditions of reaction. In the case of BMS, the reaction mechanism can correspond to either a typical electrophilic anti addition process, the intermediate being a chloronium bridge ion subsequently attacked in the $\alpha$ position of the phenyl ring by a water molecule, or to the formation of an epoxide, free or ligated to the metal, being attacked in the least-hindered $\beta$ position by a chloride. As an epoxide was detected in the case of MOS oxidation, the behavior of the 2-methyl-3-phenyloxirane (BMS-epoxide) was investigated under oxidative conditions. When 500 eq. of epoxide was added to the standard reaction conditions in the presence of EcNikA-Ru1/2, only 1-phenylpropane-1,2-diol was detected with a yield of $96 \%$, whereas in the presence of EcNikA or Ru1, the epoxide was recovered unchanged. Compared to the exclusive formation of chlorohydrin when BMS is the substrate, it is clear that free BMS-epoxide is not formed. Moreover, oxidant was required for the diol formation, indicating that the hybrid catalyst needs to be oxidized, either to bind the epoxide or to activate a bound water molecule. 
We then investigated the possible formation of a chloronium bridge ion as an intermediate of the reaction. $\mathrm{PhICl}_{2}$ has been described to generate such an intermediate when reacted with carboncarbon double bonds. ${ }^{15}$ Moreover, the presence of small amounts of chlorohydrin in the uncatalyzed reaction could be related to the presence of additional hypervalent iodine species in aqueous solution when PIDA is mixed with Tris. $\mathrm{HCl}$ buffer. Indeed, ${ }^{1} \mathrm{H}$ NMR study of a scaled-up, uncatalyzed reaction mixture revealed that a new species slowly appeared as a function of time with chemical shifts of 7.20 $(\mathrm{t}), 7.43(\mathrm{t})$ and $7.80(\mathrm{~d}) \mathrm{ppm}$ for aromatic protons. These shifts values are identical those of $\mathrm{PhICl}_{2},{ }^{16}$ suggesting the presence of such a species in solution in the absence of the hybrid catalyst. The formation of $\mathrm{PhICl}_{2}$ in buffered solution results from a nucleophilic attack of chlorides on the hypervalent iodine and the removal of the acetate anions. This hypervalent iodine transformation could also be catalyzed by the hybrid, as has been observed in $\mathrm{CH}_{3} \mathrm{CN}: \mathrm{H}_{2} \mathrm{O}$ mixtures with $\mathrm{RuCl}_{3} \cdot{ }^{17}$ Therefore, we replaced PIDA with $\mathrm{PhICl}_{2}$ under catalytic conditions (Figure 3). When MOS was the substrate, $\mathrm{PhICl}_{2}$ was able to catalyze the formation of the previously unobserved corresponding chlorohydrin (35\% yield) without forming any epoxide, attesting of the absence of $\mathrm{PhICl}_{2}$ as a free oxidative species in our standard catalytic conditions.

Finally, it is well documented that the reaction of a metal with a hypervalent iodine leads mostly to the formation of a high-valent metal-oxo species, with the oxygen atom coming from a water molecule (except for PhIO) or an oxygenated substituent such as acetate in PIDA. ${ }^{15 b, 18}$ In fact, it has been demonstrated that Ru-OH $\mathrm{OH}_{2}$ systems could be oxidized with a two-electron oxidation and the release of protons. Two competitive reactions between free $\mathrm{Cl}^{-}$and a high-valent ruthenium-oxo $\left(\mathrm{Ru}^{\mathrm{IV}}(\mathrm{Cl})=0\right)$ can then be considered i) the production of free $\mathrm{Cl}^{+}$by direct chloride oxidation, ii) the formation of hypochlorite, the latter being described in several examples of bioinspired chloroperoxidase systems. Nevertheless, the $\mathrm{Ru}^{\mathrm{IV}}(\mathrm{Cl})=\mathrm{O}$ could lead to the chlorination of alkenes in a similar fashion to iron $\alpha$-ketoglurate dependent enzymes. ${ }^{19}$ In these cases, the metal-oxo species was only an oxidant species without any oxygen atom transfer (HAT mechanism). This putative metal-oxo species is also analogous to iron-based oxidizing species involved in cis-dihydroxylation catalyzed by the macrocyclic tetraaza ligand. ${ }^{5 c, 20}$ In our case, the formation of a chlorohydrin as the sole product during oxidation of MOS in the presence of sodium hypochlorite (Figure 3) led us to finally neglect the presence of a chloronium ion bridge as an intermediate. Conversely, when PhIO, a reactant known to generate only metal-oxo species, ${ }^{18 c, 21}$ replaced PIDA (Figure 3), the reaction specificity was conserved while the yield dropped to $12 \%$ (probably due to the polymeric form of $\mathrm{PhIO}$ ). In the case of MOS, the formation of an epoxide is also consistent with a classic oxidation pathway in the presence of $\mathrm{Ru}^{\mathrm{IV}}(\mathrm{Cl})=0 .{ }^{22}$

The hydroxychlorination mechanism may also be related to the existence of other oxidizing species. First, the literature describes a metal-based mechanism that allows the disproportionation of PIDA into 
iodobenzene $(\mathrm{Phl})$ and iodylbenzene $\left(\mathrm{PhlO}_{2}\right) .{ }^{23} \mathrm{PhlO}_{2}$ is known to oxidize alcohols and alkanes and could then be present in our reaction medium. The involvement of $\mathrm{PhIO}_{2}$, generated by $\mathrm{RuCl}_{3}$, was ruled out by the formation of only traces of chlorohydrin in the case of BMS oxidation (Figure 3). ${ }^{17}$ Second, the formation of a dioxo $\mathrm{Ru}(\mathrm{VI})$ species is rejected on the basis of its propensity to cleave alkenes into aldehydes or to generate diols. ${ }^{24}$

The hypothesis of a unique oxidizing species for both formation of chlorohydrin and epoxide was challenged by UV-visible kinetic experiments (Figure S1). Treating EcNikA-Ru1 with 50 eq. of PIDA led to the formation of a new species characterized by an absorption at $560 \mathrm{~nm}$, while no change was observed in the presence of Ru1 alone. Addition of 500 eq. of either BMS or MOS to this solution led to the rapid loss of this new species upon time, supporting that it is an oxidizing intermediate in both reaction pathways (Figure S1A).The same species could be observed when NikA-Ru1 was treated with a same amount of PhIO (Figure S1B). The absorbance was then lower in accordance with the lower reactivity observed when PhIO was used as the oxidant (Figure 3). Consequently, this common behavior suggest the hypothesis of the formation of a $\mathrm{Ru}=\mathrm{O}$ oxidizing species. ${ }^{21 d}$ Following our modelisation approach for the IR spectrum (see above), we calculated the UV-visible spectrum of the suggested $\mathrm{L}(\mathrm{CO})(\mathrm{Cl}) \mathrm{Ru}=\mathrm{O}$ species using the Gaussian 09 program package and the hybrid exchangecorrelation B3LYP functional in conjunction with the $6-311++G(d, p)$ basis set and long range dispersion correction. Optimization was carried in the presence of chlorobenzene solvent by applying the integral equation formalism for the polarizable continuum model (IEF-PCM). Then, spectra were obtained using time-dependent density functional theory (TD-DFT) both in absence and in presence of five protein residues (Arg137, Tyr22, Tyr402, Trp100 and Trp398) maintaining their $\alpha$ and $\beta$ carbons fixed to mimic the presence of the protein. In vacuum, two transitions were visible in the 500-700 $\mathrm{nm}$ range $(\lambda=563$ and $605 \mathrm{~nm})$ resulting in an average large band centered around $585 \mathrm{~nm}$ when a dispersion corresponding to $\sigma=0.2 \mathrm{eV}$ was applied to the spectrum (Figure S1C). The band at $563 \mathrm{~nm}$ corresponds to a transition from the HOMO $\beta$ anti-bonding orbital between $\mathrm{Ru}$ and $\mathrm{Cl}$ atoms to the second $\beta$ antibonding virtual orbital located between $\mathrm{Ru}$ and $\mathrm{O}\left(\pi->\pi^{*}\right)$. A second transition was also calculated around $450 \mathrm{~nm}$, that was hidden by the absorption of excess PIDA in the experimental spectrum and the Ru1 and NikA as well (Figure S1). In presence of the protein residues, similar observations were made but resulting in an even broader band. The concordance of energy bands between theory and experiments supports the hypothesis of a the formation of an oxidizing $\mathrm{L}(\mathrm{CO})(\mathrm{Cl}) \mathrm{Ru}=\mathrm{O}$ species.

The absence of more direct positive experimental proofs urged us to explore both the epoxidation and chlorohydrination reaction mechanisms at a theoretical level as a function of substrates to define both the nature of the active species and the reaction specificity. All the above pathways including PIDA 
adducts, were then confronted to extensive calculations in order to discriminate their occurrence. When done, their compatibilty with experimental data should help to elucidate the reaction pathway.

\section{Computational studies}

The possible reaction pathways leading from MOS or BMS to epoxide and chlorohydrin were evaluated using quantum chemistry computations. Since all-electron calculations are not accessible for EcNikARu1/2, our approach consisted of modelling the Ru1 or Ru2 complex either alone or in the presence of the close amino acids residues that are involved in the ruthenium complex stabilization via supramolecular interactions.

Calculations were run using the Gaussian g09 program. ${ }^{25}$ Both singlet and triplet states were calculated for all the species presented here.

Using the DFT method with B3LYP functional, ${ }^{9}$ a def2-SVP split valence polarization basis $\operatorname{set}^{10}$ and a Polarizable Continuum Model (IEFPCM) ${ }^{26}$ for the solvent, we first examined the geometry of the starting Ru1 complex (Figure 4, top). We compared the metrics obtained from the x-ray structure of EcNikA-Ru1 ${ }^{4}$ (PDB code: 5L8D, Figure 2 top right) with the computed ones of the complex in the singlet $(S=0)$ and triplet $(S=1)$ state. The involvement of the protein scaffold has been partially modelled by adding five residues (Arg137, Tyr22, Tyr402, Trp100 and Trp398) to the calculations. Only the modelled triplet state showed similar CO bond lengths to the crystal structure. Most importantly, the modelled triplet state predicted the curvature of the $t \mathrm{CO}$ at the cost of the $\mathrm{Ru}-\mathrm{O}_{\text {carb }}$ length. However, the triplet state Ru1 is nearly $50 \mathrm{kcal} \mathrm{mol}^{-1}$ higher in energy than the singlet state, prohibiting its existence in solution. Subsequently, Ru2, observed by x-ray crystallography, was modelled (Figure 4, bottom). The modelled structure more closely matches the bond lengths and angles observed in the crystal structure of EcNikA-Ru2 (PDB code: 6R4Q, Figure 2, bottom right) when the singlet state is considered. This result was replicated when the complex was modelled in the absence of the nearby residues (Figure S2). Altogether, these observations validate the calculation methodology employed and lead us to describe Ru1 and Ru2 as $\mathrm{S}=0$ species. 

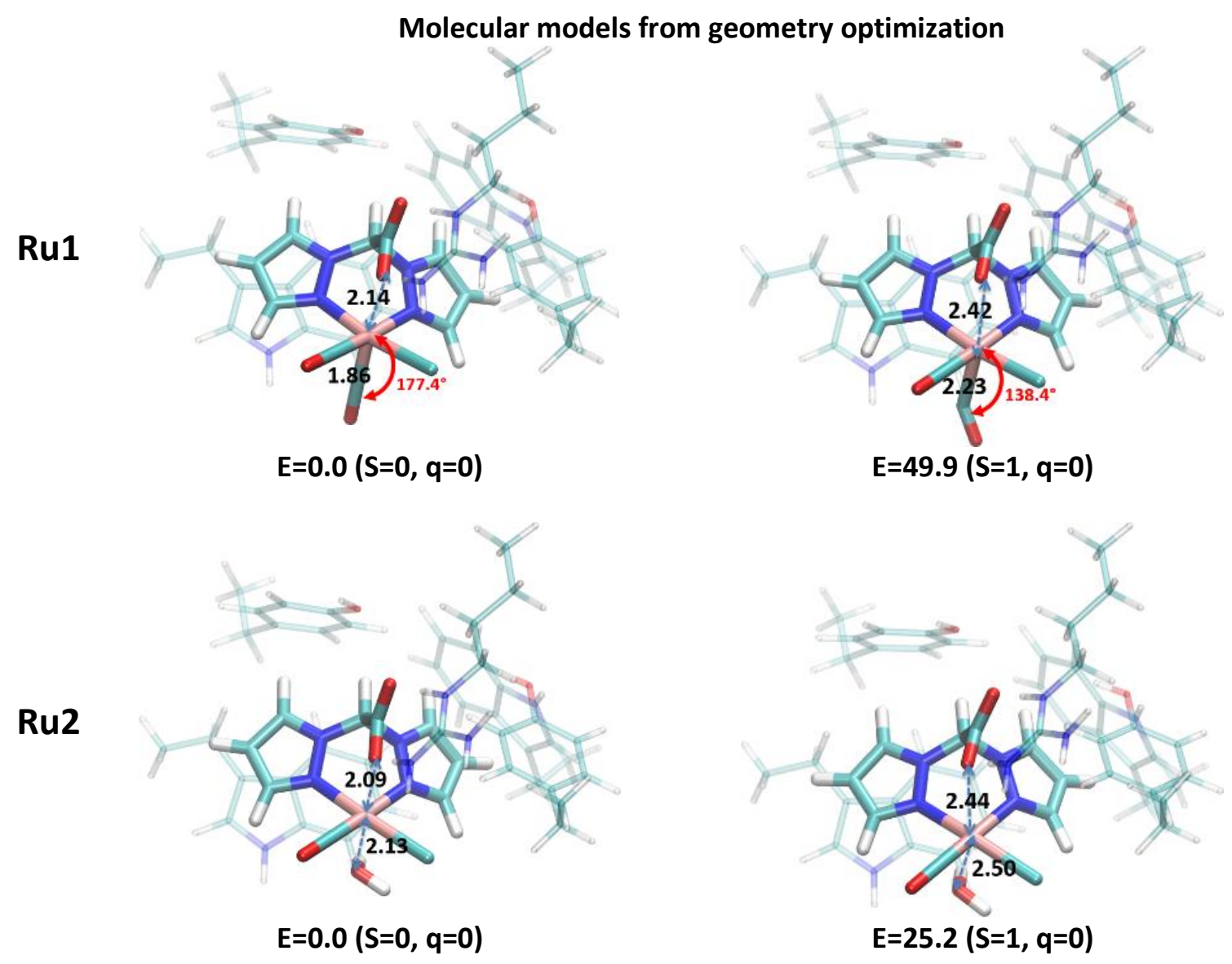

Figure 4. Comparison of bond lengths (black) and angles (red) of modelled Ru1 in the presence of five amino acids in the singlet $(\mathrm{S}=0)$ and triplet $(\mathrm{S}=1)$ states (first line) and modelled Ru2 in the presence of five amino acids in the singlet and triplet states (second line). All energies in $\mathrm{kcal} \mathrm{mol}^{-1}$. The $\mathrm{Ru}-\mathrm{OH}_{2}$ and $\mathrm{Ru}-\mathrm{O}_{\text {carb }}$ bonds are present even if not drawn by the program.

In order to discriminate between active species, two relevant forms of the ruthenium complex (activated by PIDA in the presence of $\mathrm{NaCl}$ ) were considered: $\mathrm{Ru}^{\mathrm{IV}}(\mathrm{Cl})=\mathrm{O}$ and $\mathrm{Ru}^{\prime \prime}(\mathrm{Cl})(\mathrm{OCl}$ ) (Figure 5). Epoxidation is well described in the literature as being related to the presence of hypervalent oxo species, while Ru"OCl can be a source of chloronium for chlorination. ${ }^{18 d, 24,27}$

$\mathrm{Ru}^{\prime \prime}(\mathrm{Cl})(\mathrm{OCl})$ is more stable in the singlet state $\left(28.0 \mathrm{kcal} \mathrm{mol}^{-1}\right.$ lower in energy than the triplet state) but the charge on the chloronium atom is only 0.07 , making it a weak electrophile. Similarly, calculations attempted to make $\mathrm{Ru}^{\prime \prime}(\mathrm{Cl})(\mathrm{OCl})$ react with alkenes led to a non-conclusive pathway. Considering these results, the hypothesis of $\mathrm{Ru}^{\prime \prime}(\mathrm{Cl})(\mathrm{OCl})$ being the active oxidation species was discarded. The $\mathrm{Ru}^{\mathrm{IV}}(\mathrm{Cl})=\mathrm{O}$ complex is more stable in the triplet spin state than in the singlet state by $15.7 \mathrm{kcal} \mathrm{mol}^{-1}$ but in both cases, atomic partial charges do not account for an electrophilic character of the double-bonded oxygen atom or the chlorine atom. 


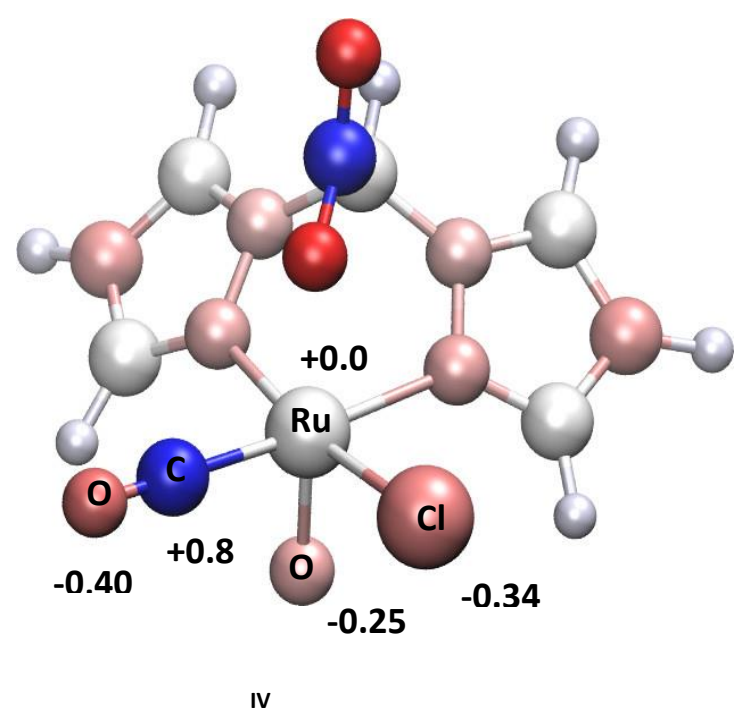

$\mathrm{Ru}(\mathrm{Cl})=\mathrm{O}$

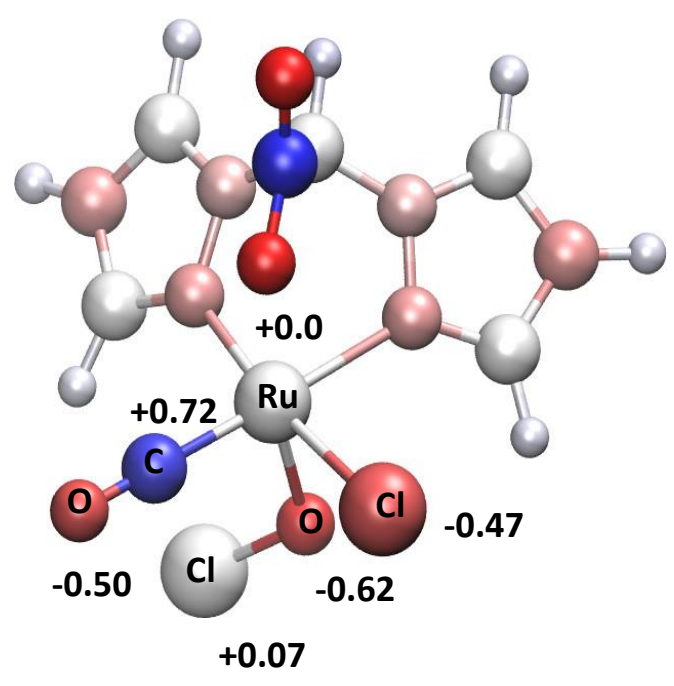

$\mathrm{Ru}$ "(Cl)(OCl)

Figure 5. Atomic partial charges and geometry of the $\mathrm{Ru}^{\mathrm{IV}}(\mathrm{Cl})=\mathrm{O}$ (charge 0 , spin 1 ) and $\mathrm{Ru}(\mathrm{Cl})(\mathrm{OCl})$ (charge -1 , spin 0 ) activated complexes. Sizes and colors of balls are representative of relative atomic partial charges. The Ru-Ocarb bond is present even if not drawn by the program.

The reaction mechanisms of hypervalent iodine compounds with metal complexes are poorly described in the literature, with only few examples of iron complexes and even fewer with ruthenium. ${ }^{27-28}$ Although no active ruthenium oxidant has been directly observed in EcNikA-Ru1/2, all empirical evidence points towards the existence of a metal-centered species responsible for transferring an oxygen atom during catalyzed epoxidation. To assess the process by which the oxidant acts on the ruthenium center, it was necessary to probe the reaction between Ru1/2 and PIDA using small QM models. These calculations did not evidence any reactivity between Ru1 and PIDA. Conversely, after geometry optimization of Ru2, a symmetrical hydrogen bonding structure was obtained prior to any reactivity (species (a), Figure 6 ). The $C=0$ groups of each acetate moiety became angled towards the protons of the bound water. The reduction in energy caused by such an interaction is magnified due to the absence of explicit water molecules, which would provide alternative hydrogen bonding opportunities when the oxidant and Ru2 are well separated. Explorative calculations were trialed using explicit solvent (1-5 molecules of $\left.\mathrm{H}_{2} \mathrm{O}\right)$; however, the additional degrees of freedom associated with explicit solvent molecules led to sampling issues with false energy minima, along with a significant increase in computational cost. The formation of a bond between the bound water and iodine of the oxidant led to the release of a single acetate group (species (b), Figure 6), maintaining the triply bonded hypervalent iodine motif and liberating a proton from the water. Similar energetic barriers were found for the initial attack of the iodine on the water in the $S=0$ and $S=1$ states $(21.0$ and $19.3 \mathrm{kcal} \mathrm{mol}^{-1}$, respectively). However, the intermediate $\mathrm{Ru}^{\prime \prime}$ species was found to be relatively 
unstable in the triplet state. When the iodine was pulled away from the ruthenium complex using a potential energy surface (PES) scan, species (b) underwent simultaneous breakage of both I-O bonds, releasing free $\mathrm{AcOH}$ and $\mathrm{Phl}$. The iodine gained two electrons from the oxygen of the Ru-bound water, at which point the formal oxidation state of the ruthenium center changed from +2 to +4 , and the $\mathrm{Ru}$ $\mathrm{O}$ bond shrank from $2.01 \AA$ to $1.81 \AA$, indicating that a $\mathrm{Ru}=\mathrm{O}$ had formed. Unlike the singlet-state pathway, no intermediate species were observed between $(\mathbf{b})$ and the $\mathrm{Ru}^{\mathrm{IV}}(\mathrm{Cl})=\mathrm{O}$ (species (d), Figure 6). In the singlet state, species (b) was found to be stable, but significantly higher in energy than its separate components (species (a), Figure 6). Upon removal of the second acetate group and proton (species (c), S=0 pathway), the energy increased by a further $15.3 \mathrm{kcal} \mathrm{mol}^{-1}$, yet the $0-\mathrm{I}$ bond remained intact. The stability of such a relatively high-energy species is testament to the resistance of the singlet state complex to form an oxo species. When the remaining Phl group was removed by PES scan, followed by a reoptimization, the $\mathrm{Ru}^{\mathrm{IV}}(\mathrm{Cl})=\mathrm{O}$ was observed (species $(\mathbf{d})$ ).

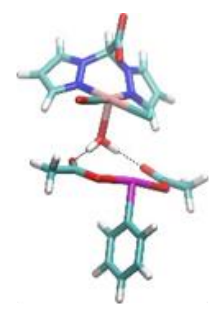

(a)

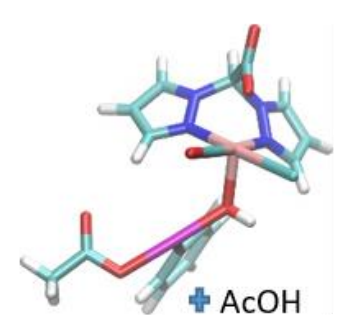

(b)

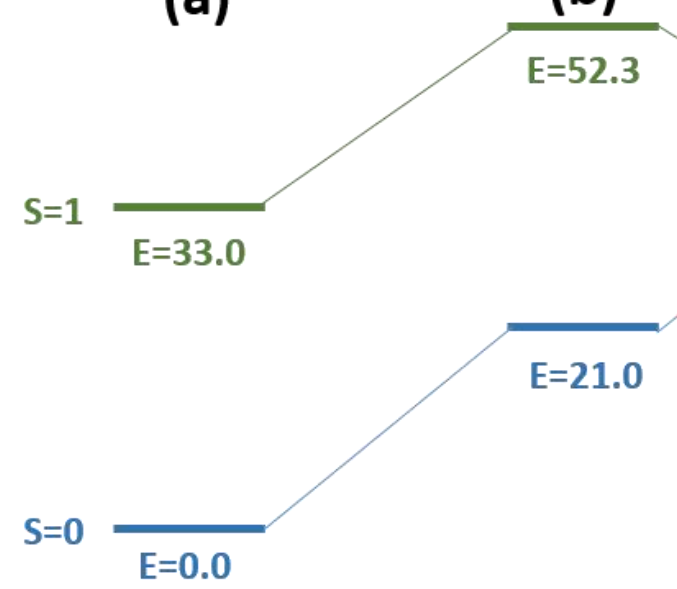

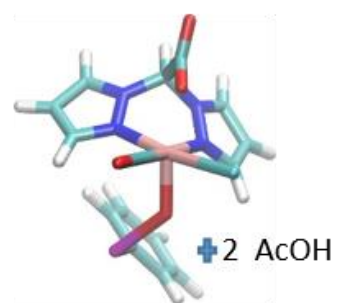

(c)

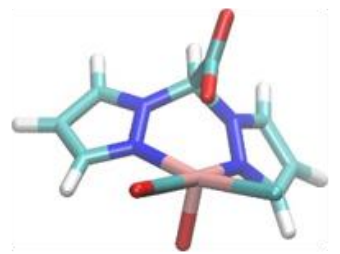

(d)
$+2 \mathrm{AcOH}$

$+\mathrm{Phl}$ 
were pursued. Firstly, it is possible that singlet multiplicity is maintained throughout, and that the active oxidant in the EcNikA-Ru1/2 catalytic cycle is the species (b), $\mathrm{S}=0$ (blue pathway).

Secondly, in the triplet state (green pathway), both the initial energy and the energy barriers seem to preclude a pathway between reactants and products. However, the calculations present several shortcomings. The implicit solvent conditions may not account for the dielectric constant inside the protein cavity, and the calculations do not take into account the gain in entropy resulting from the liberation of the $\mathrm{AcOH}$ and $\mathrm{Phl}$ molecules. The size of the considered molecules excluded rigorous $\mathrm{QM} / \mathrm{MM}$ calculations with the protein present. It has been shown in the literature that similar transition metal species can change their spin state during redox reactions. ${ }^{27,29}$ It is therefore possible that the ruthenium center undergoes a change in spin state upon oxidation, with the reactants beginning in the singlet state, and ending in the triplet state oxo, as shown by the red arrow and a third path on Figure 6.

Therefore, the active oxidizing species could be the $\operatorname{Ru}^{\mathrm{IV}}(\mathrm{Cl})=\mathrm{O}$ species (d) (singlet or triplet state), or the ruthenium-iodine adduct (c). In order to make a decision, the MOS carbon-carbon double bond was moved towards the oxygen atom of the singlet state species (c), minimizing the energy at each step along a PES scan. No thermodynamically viable reaction pathway was obtained for this system. Indeed, a single well-defined minimum energy path for the approach of the olefin was difficult to obtain and resulted in very high-energy barriers. This calculation was repeated, scanning the alkene towards the iodine atom in an attempt to form the iodinium cation species proposed by Yang et al., ${ }^{30}$ but again, no low energy reaction path was found. These results led us to consider $\operatorname{Ru}^{\mathrm{IV}}(\mathrm{Cl})=\mathrm{O}$ (d) as the only possible active oxidizing species for the oxidation of MOS and BMS. To cope with the problem of weak, non-bonded interactions between $\mathrm{Ru}^{\mathrm{IV}}(\mathrm{Cl})=\mathrm{O}$ and the substrates before the reaction (absent with the B3LYP density functional), an empirical dispersion correction (GD3BJ) ${ }^{31}$ term was added in the calculations.

We then investigated substrate oxidation reactions. An energetic pathway was mapped out for the complex in both $\mathrm{S}=0$ and $\mathrm{S}=1$ states. In the case of MOS, a summary of the computations is presented in Figure 7 (see Figure S3 for all the calculated structures and Table S5). The starting point is species (e), the $\mathrm{Ru}^{\mathrm{IV}}(\mathrm{Cl})=\mathrm{O}$ complex (species (d), Figure 6) in the presence of MOS. In the case of $\mathrm{S}=0$, close-shell calculations led to only one transition state (TS1) slightly uphill $\left(6.4 \mathrm{kcal} \mathrm{mol}^{-1}\right)$, which gave the epoxide product $(\mathbf{g})$ downhill by $37.1 \mathrm{kcal} \mathrm{mol}^{-1}$. In the case of $S=1$, two competing pathways were observed, following an attack of the oxygen atom on either the $\alpha$ or the $\beta$ carbon atom of the double bond. In both cases, we observed a two-steps mechanism. Initial attack on the $C \beta$ led to an overall lower energy pathway. The first transition state (TS2) was significantly lower than when C $\alpha$ attack was 
considered (7.5 vs $\left.17.1 \mathrm{kcal} \mathrm{mol}^{-1}\right)$ and the second energy barrier was computed to be $11.7 \mathrm{kcal} \mathrm{mol}^{-1}$ lower than for the attack on the C $\alpha$. As expected, spin and NPA charge calculations demonstrated that a radical species is formed on the carbon atoms and a Ru(III) in (TS2), (species (f) and (h), Figure 7, Table S6). The intermediate is better stabilized $\left(-13.3\right.$ vs $\left.3.5 \mathrm{kcal} \mathrm{mol}^{-1}\right)$ when the radical is located on the $\mathrm{C} \alpha$ atom (f). Nevertheless, the two pathways give the same epoxide product (species (g), Figure 7). Comparing all pathways, the only observed product is the unique epoxide (g).

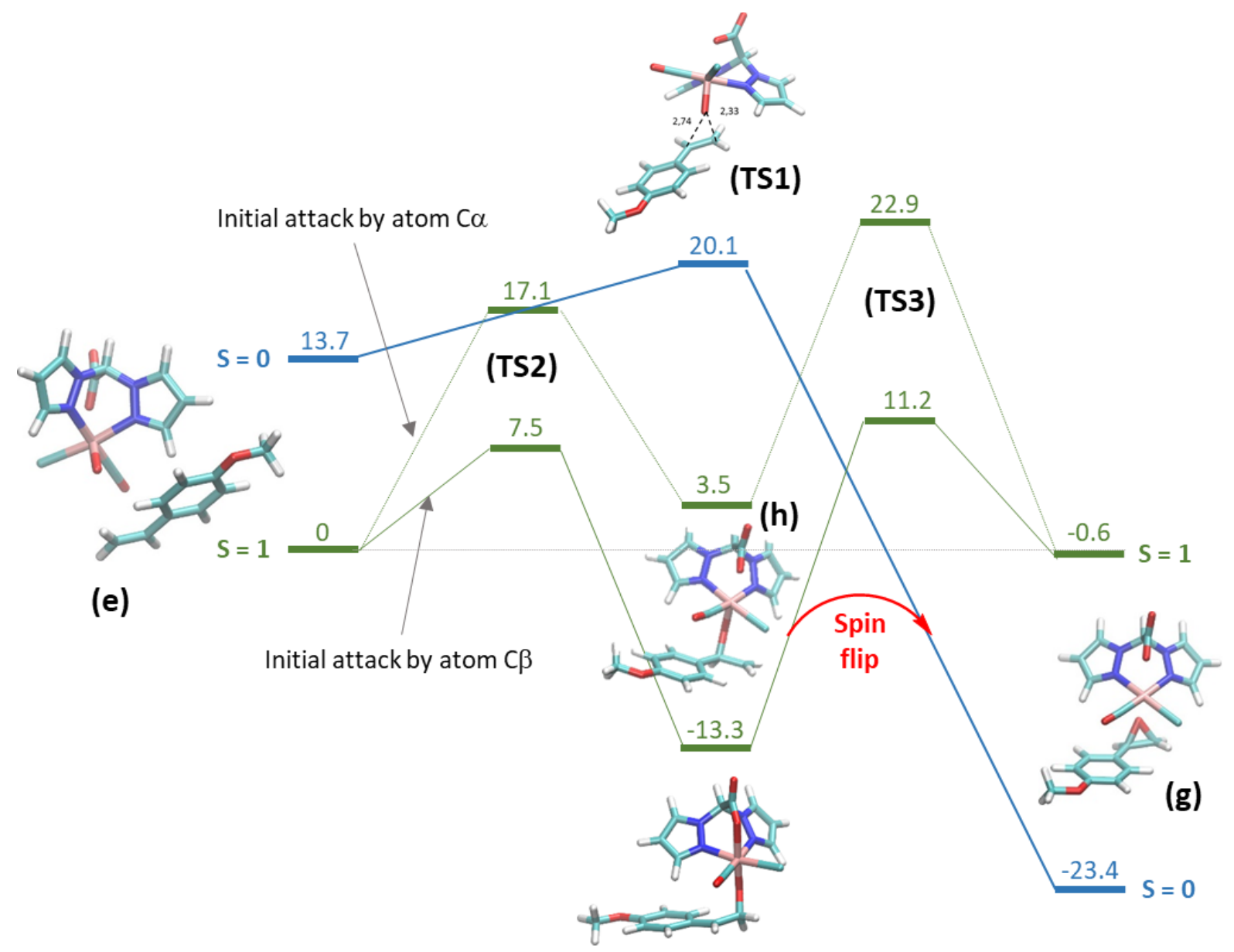

(f)

Figure 7. Reaction diagram showing the B3LYP calculated energies for epoxidation of MOS, catalyzed by $\mathrm{Ru}^{\mathrm{IV}}(\mathrm{Cl})=0 . S=1$ state calculations are shown in green, and the close shell $\mathrm{S}=0$ process in blue. Energies given in $\mathrm{kcal} \mathrm{mol}^{-1}$ relative to the energy of the starting species in $\mathrm{S}=1$ state. The Ru-Ocarb bond is present even if not drawn by the program.

Next, we examined the reaction mechanism on BMS. Again, an energetic pathway was mapped out for the complex in both $\mathrm{S}=0$ and $\mathrm{S}=1$ states (Figure 8; see Figure $\mathrm{S} 4$ and Table $\mathrm{S} 5$ for all calculated structures). The starting point is the species (i): the $\operatorname{Ru}^{\mathrm{IV}}(\mathrm{Cl})=0$ complex (species (d), Figure 6) in the presence of BMS. In the case of $\mathrm{S}=0$, close shell calculations led to a nearby transition state (TS4) (only 
$2.9 \mathrm{kcal} \mathrm{mol}^{-1}$ uphill), followed directly by product (j) downhill by $33.1 \mathrm{kcal} \mathrm{mol}^{-1}$. Surprisingly, this product is not the predicted epoxide, but rather a chlorohydrin. In the case of $\mathrm{S}=1$, we again compared the two competing pathways following an attack of the oxygen on either the $\alpha$ or $\beta$ carbon. As expected, an initial attack on the $C \beta$ led to lower energy barriers, with (TS8) lying $7.4 \mathrm{kcal} \mathrm{mol}^{-1}$ lower than (TS5), and an energy lowered by $12.0 \mathrm{kcal} \mathrm{mol}^{-1}$ for the radical intermediate (k) (Table S6).

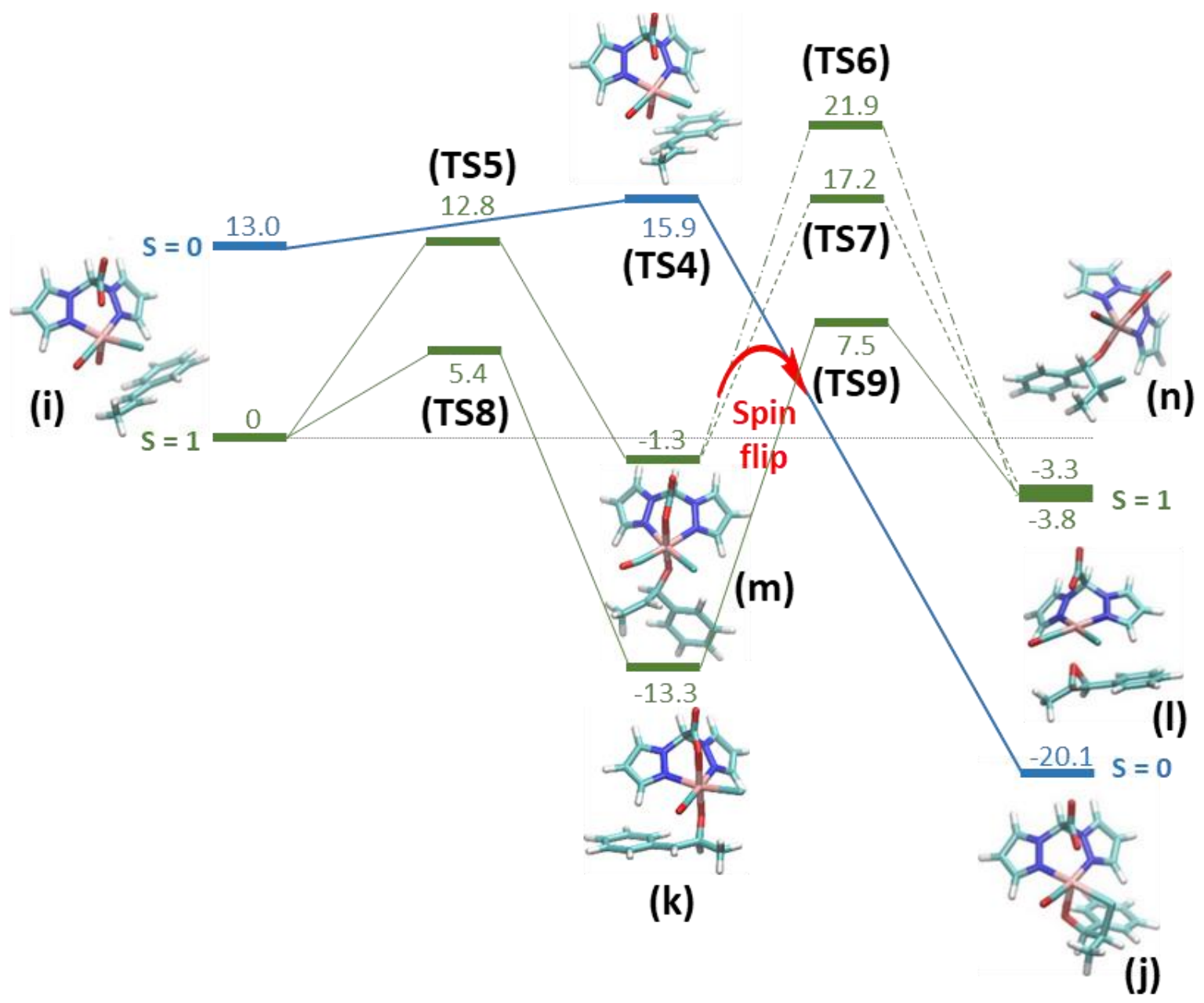

Figure 8. Reaction diagram showing the B3LYP calculated energies for epoxidation and hydroxychlorination of $B M S$, catalyzed by $\operatorname{Ru}^{\mathrm{IV}}(\mathrm{Cl})=0 . \mathrm{S}=1$ state calculations are shown in green, and the close shell $\mathrm{S}=0$ process in blue. Energies given in $\mathrm{kcal} \mathrm{mol}^{-1}$ relative to the energy of the starting species in $\mathrm{S}=1$ state. The Ru-Ocarb bond is present even if not drawn by the program.

Nevertheless, following the reaction from (k) via TS9 was found to lead only to the epoxide (I). Looking carefully at the structure of (k) (Figure S4C, spacefill representation), it was possible to identify an important interaction between the chlorine atom held by the ruthenium and the methyl group of BMS, avoiding the rotation necessary to a subsequent chlorohydrination. The other possible pathway 
followed an attack on the $\mathrm{C} \alpha$ through (TS5). The radical intermediate $(\mathbf{m})$ could evolve to both epoxide (I) and chlorohydrin (n) via activation barriers of $18.5 \mathrm{kcal} \mathrm{mol}^{-1}$ (TS7) and $23.2 \mathrm{kcal} \mathrm{mol}^{-1}$ (TS6), respectively. Comparing all the pathways, the thermodynamic product is the unique chlorohydrin (j) in the singlet state.

Looking for differences between the reactivity of radical intermediates $(\mathbf{m}),(\mathbf{k})$ and $(\mathbf{f})$ coming from BMS and MOS, respectively, we explored the PES depending on the orientation of the substrate facing the chlorine atom (Table S7). In the case of MOS, the shortest distance between the chlorine and the radical carbon is $4.37 \AA$, while in the case of BMS, the distance ranges between 3.38 and $5.46 \AA$. One of the shortest (3.64 $\AA$ ) is found for intermediate (m) (Figure 8) at $-1.3 \mathrm{kcal} \mathrm{mol}^{-1}$ which may lead to the formation of a $\mathrm{Cl}-\mathrm{C} \beta$ bond and hence the chlorohydrin.

Finally, we recalculated the majority of the reaction paths in the presence of the protein. Quantum calculations in the presence of protein residues surrounding the active site demand high computational resources. They were thus restricted to the closest environment in the reaction pathways. Residues in immediate proximity to the complex are arginine 137 (interacting with the carboxylate of the Ru complex), tyrosines 22 and 402, tryptophans 100 and 398 . $\mathrm{Ru}^{\mathrm{IV}}(\mathrm{Cl})=0$ was used as a template to correctly position BMS and MOS (in complex with $\mathrm{Ru}^{\mathrm{IV}}(\mathrm{Cl})=0$ ) in the different conformations presented above but inside the protein. The coordinates of BMS and MOS were obtained by least square superimposition of the template in vacuum versus in the protein (reduced to 5 amino acids). The $C \alpha$ and $C \beta$ atoms of the five protein residues (with coordinates taken from the $x$ ray structure) were fixed during the calculations. All of the results are presented in Table S8.

For BMS, the energies along the reaction paths were comparable with or without the protein residues. For example, the transition state corresponding to O-C $\alpha$ bond formation ((TS4) in Figure 8) was retrieved (Figure 9, top left). This transition state led to the 5 -atom ring with $\Delta \mathrm{E}=-36.7 \mathrm{kcal} \mathrm{mol}^{-1}$ (comparable to $-36 \mathrm{kcal} \mathrm{mol}^{-1}$ from (TS4) to (j) in the absence of the protein). In the case of MOS oxidation, the singlet state could not be calculated, as we were unable to characterize a transition state where MOS would not clash with Trp398 (Figure 9, top right). Another limitation imposed by the protein is illustrated in the case of the formation of an epoxide from BMS: no analog of product $\left(\mathbf{g}^{\prime}\right)$ could be computed when replacing MOS with BMS, since the methyl group clashes with the same Trp398 (Figure 9, Bottom right).

Exploring the PES for the most stable species, we found another impact of the protein on the reaction. There are relative conformations of the substrate and Ru complex, equivalent to states (e) or (i), with lower energies but non-reactive. For example, relaxation of (TS2) for MOS led to an equivalent of (e) but lying $2.6 \mathrm{kcal} \mathrm{mol}^{-1}$ downhill (Table S9). The effect is even clearer for BMS and MOS in open-shell 
singlet state configurations, where energy reductions of 9.9 and $12.2 \mathrm{kcal} \mathrm{mol}^{-1}$ were obtained, respectively, when allowing structures incompatible with the presence of the protein. Note also from Table S9 that the lowest reactive MOS orientation in the singlet state, compatible with the protein, has an energy of $16.4 \mathrm{kcal} \mathrm{mol}^{-1}, 2.7 \mathrm{kcal} \mathrm{mol}^{-1}$ higher than structure (e) presented in Figure 7 . When these lowest energy species are superimposed on the 5 amino acids representing the protein, the stabilized substrate always clashes with Trp398 (Figure S5). We therefore concluded that the main role of the protein might be to preclude the formation of these stable unreactive species, rather than lower the barrier between reactants (reactive species) and products.
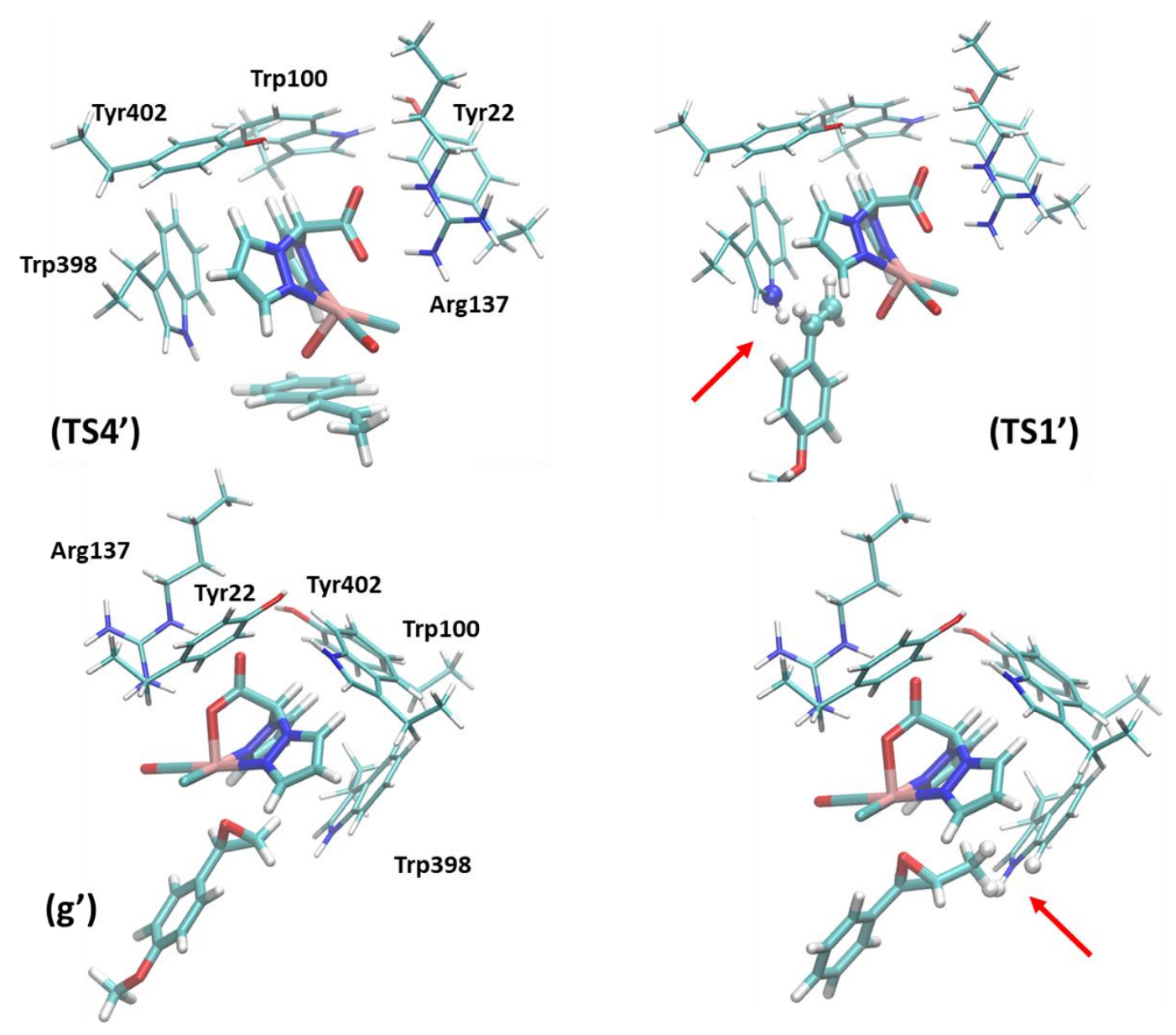

Figure 9. Top: Transition states for product formation between $\mathrm{Ru}^{\mathrm{IV}}(\mathrm{Cl})=\mathrm{O}$ and BMS ((TS4'), left) or MOS ((TS1'), right), open shell singlet states, in the presence of surrounding protein residues. Note the steric clash between MOS and Trp398 highlighted with CPK spheres for atoms closer than $2 \AA$ from each other. Bottom: Epoxide complexes between $\mathrm{Ru}^{\mathrm{IV}}(\mathrm{Cl})=\mathrm{O}$ and $\mathrm{MOS}\left(\left(\mathbf{g}^{\prime}\right)\right.$, left) or BMS (putative, right), singlet state, in the presence of surrounding protein residues. Note again the steric clash between BMS and Trp398. The Ru-Ocarb bond is present even if not drawn by the program. 


\section{Discussion}

All experimental observations led us to rule out a mechanism with a chloronium bridge ion as an intermediate, and instead suggested the formation of $\mathrm{Ru}^{\mathrm{IV}}(\mathrm{Cl})=\mathrm{O}$ as the sole (terminal) oxidizing species (common behavior between PhIO and PIDA, observation of an electronic transition for an oxidizing intermediate indicative of high valent ruthenium and finally the formation of epoxide). The catalytic behavior of EcNikA-Ru1 was then evaluated computationally in order to decipher the reaction pathway, taking into account the chemoselectivity, regioselectivity and stereoselectivity observed. First of all, it has to be noted that, due to computational costs, it would have been impossible to examine all models encountered in the complete pathways using the full hybrid structure by QM/MM. Accordingly, Ru1 and the reactivity of Ru2 with PIDA were investigated. Computations showed that Ru1 is not an active species. Subsequently, it was proposed that the combined electron withdrawing effects of the ruthenium center of Ru2 and the bound proton could all contribute to a heightened electrophilicity of an 'activated water' species. This facilitates a nucleophilic attack on the hypervalent iodine atom of PIDA to form the $\mathrm{Ru}^{\mathrm{IV}}(\mathrm{Cl})=\mathrm{O}$ species, through a Ru-O-IPh intermediate, shown in a genuine calculated energy profile. All other possible reaction pathways were found too costly energetically. Hence, the $\mathrm{Ru}^{\mathrm{IV}}(\mathrm{Cl})=\mathrm{O}$ was determined as the active species for the epoxidation of MOS and hydroxychloration of BMS.

We first examined the case of MOS. In the $\mathrm{S}=0$ state, the formation of the epoxide proceeds in a single step with a low barrier of $6.4 \mathrm{kcal} \mathrm{mol}^{-1}$, and is highly exothermic $\left(\Delta \mathrm{E}=-37.1 \mathrm{kcal} \mathrm{mol}^{-1}\right)$. The spin-state and NPA charge calculations evidenced the oxidation state conservation on the ruthenium and the absence of radical or carbocation character on the MOS molecule (Table S6). Moreover, the final product $(\mathbf{g})$ shows a spin increase on the ruthenium, attesting of the reduction of the ruthenium ion during the process. This was expected for two reasons: firstly, the $\mathrm{Ru}^{\mathrm{IV}}(\mathrm{Cl})=\mathrm{O}$ complex is far less stable in the singlet state than in the triplet ground state $\left(\Delta \mathrm{E}=13.7 \mathrm{kcal} \mathrm{mol}^{-1}\right)$, leading to a higher initial energy of the reactants. Secondly, following the reduction of $\mathrm{Ru}(\mathrm{IV})$ to $\mathrm{Ru}(\mathrm{II})$, the singlet state becomes notably more stable than the triplet $\left(\Delta \mathrm{E}=-22.8 \mathrm{kcal} \mathrm{mol}^{-1}\right)$. Interestingly, open shell energies for the singlet states (e) and (TS1) are significantly reduced compared to close shell values reported above from 13.7 to 4.2 and from 20.1 to $15.6 \mathrm{kcal} \mathrm{mol}^{-1}$, respectively (Table S5). The initial barrier thus increases from 6.4 to $11.4 \mathrm{kcal} \mathrm{mol}^{-1}$ and the triplet pathway remains more favorable.

In the triplet state, the path of $\alpha$-carbon attacking first is clearly disfavored when compared with the $\beta$-carbon attack. Not only does the stability of the triplet-state intermediate increase $(\Delta \mathrm{E}=16.8 \mathrm{kcal}$ $\left.\mathrm{mol}^{-1}\right)$, but the initial transition state (TS2) is also lowered in energy $\left(\Delta \mathrm{E}=9.6 \mathrm{kcal} \mathrm{mol}^{-1}\right)$. The second transition state (TS3) then requires $19.4-24.5 \mathrm{kcal} \mathrm{mol}^{-1}$ relative to the stable intermediates. The height of this barrier is problematic for a catalytic process, and begs the question of why these stable 
intermediates have never been observed. A possible solution rests on the ability of the ruthenium center to change its spin state. Once the first low barrier (TS2) has been overcome, the oxo ligand is inserted into the double bond and the ruthenium center is no longer Ru(IV). Analysis of the (TS3) and the final product indicates a $\mathrm{Ru}(\mathrm{II})$ state, as the spin on the ruthenium atom increases to close to 2 and no residual spin is present on the $C \beta$. Therefore, the enhanced stability afforded by the $S=1$ state disappears, and $\mathrm{S}=0$ becomes strongly favored. In summary, if the ruthenium center was able to switch from $S=1$ to $S=0$ following the formation of the first $C-O$ bond, the processes afterwards would be barrierless, avoiding (TS3) (red arrow). Taken as a whole, this would result in an overall $\Delta \mathrm{E}=-23.4 \mathrm{kcal}$ $\mathrm{mol}^{-1}$ for MOS epoxidation, much more favorable than the $-0.6 \mathrm{kcal} \mathrm{mol}^{-1}$ found when the reaction is constrained to the triplet state. Iron systems have previously been described which exhibit a remarkably similar reaction profile. Iron porphyrin systems have been shown to perform barrierless, 1-step oxidations in the low spin state and stepwise radical rebound oxidations in the high spin state. ${ }^{27,29 a}$ Spin inversions have also been proposed to be crucial in epoxidation reactions catalyzed by manganese, chromium and ruthenium. ${ }^{27,29 b, 29 c}$ For example, to understand the mechanism of epoxidation by the complex $\mathrm{Cp}^{*} \mathrm{Cr}(\mathrm{O}) \mathrm{Cl}_{2}$, Hess et al. turned to first-principles theory to calculate the minimum energy crossing point between the two PES of the chromium III and V potential oxidant in doublet and quartet spin multiplicity, respectively. They determined that the surface crossing is fast and opens a lower barrier pathway. ${ }^{29 c}$ However, taking into account the whole reaction path starting from Ru2, envisaging a reaction from species $(\mathbf{a})$ to $(\mathbf{g})$ in the $S=0$ state through species $(\mathbf{d})$ and $(\mathbf{e})$ in the $S=1$ state represents two successive spin flips. A whole pathway in the $S=0$ state could also be envisaged, with the terminal oxidant being the $\operatorname{Ru}^{\mathrm{IV}}(\mathrm{Cl})=0$ complex $(\mathrm{d})$ in the $\mathrm{S}=0$ state and the driving force the strong stabilization of the product.

Finally, no intermediates leading to a chlorohydrin type product or the chlorohydrin itself was observed along all the calculated pathways. A chlorohydrin product can be modelled via a chloride attack on the epoxide, but occurs via a supplementary energy barrier of $27.4 \mathrm{kcal} \mathrm{mol}^{-1}$ (Figure S3, A), excluding its formation. When the $\operatorname{Ru}^{\mathrm{IV}}(\mathrm{Cl})=\mathrm{O}$ complex reacts with $\mathrm{MOS}$, the overall effect of introducing the olefin is a rapid, concerted epoxidation, driven by a strongly favorable two-electron reduction of $\mathrm{Ru}(\mathrm{IV})$ to $\mathrm{Ru}(\mathrm{II})$.

In the case of BMS, the most favorable path appears to be the direct formation of a chlorohydrin in the singlet spin state. In the $\mathrm{S}=0$ state, the formation of the chlorohydrin proceeds in a single step with a low barrier of $2.9 \mathrm{kcal} \mathrm{mol}^{-1}$ and is highly exothermic $\left(\Delta \mathrm{E}=-33.1 \mathrm{kcal} \mathrm{mol}^{-1}\right)$. Open-shell energy for state (i) is reduced from 13.0 to $6.4 \mathrm{kcal} \mathrm{mol}^{-1}$, while the energy of the transition state (TS4) is unchanged. The initial barrier for chlorohydrin formation would thus increase from 2.9 to $9.5 \mathrm{kcal}$ $\mathrm{mol}^{-1}$. In the triplet state, an attack on the $\beta$-carbon leads to a lower energy pathway but with an 
epoxide as the sole final product, and a higher energy level for the second transition state. The latter offers the possibility for ( $\mathbf{k}$ ) to come back to state (i) and follow the pathway of $\alpha$-carbon attacking first, affording the regioselectivity experimentally observed. Reaching (TS5) requires $12.8 \mathrm{kcal} \mathrm{mol}^{-1}$, roughly the same amount of energy as a spin flip from $S=1$ to $S=0$ for the (i) species. Then, even if (TS6) is disfavored when compared with (TS7), $\left(\Delta E=4.7 \mathrm{kcal} \mathrm{mol}^{-1}\right)$, starting from species $(\mathrm{m})$, two pathways coexist leading to the epoxide (I) and the chlorohydrin (n), respectively. Again, spin and charge calculations attest of the radical character of intermediate $(\mathbf{m})$, similar to intermediate $(\mathbf{f})$ in the case of MOS oxidation. According to these calculations, reaction of species (i) in the triplet state should result in a mixture of products with an overall $\Delta \mathrm{E}$ around $-4 \mathrm{kcal} \mathrm{mol}^{-1}$, and not the $100 \%$ chemoselectivity observed in favor of the BMS-chlorohydrin. In summary, as observed for MOS, the best overall pathway for BMS oxidation would follow a pathway from (a) to (j), both in the singlet state after two spin flips from $S=0$ to 1 and back to 0 , but with an initial reaction between the $\mathrm{Ru}^{\mathrm{IV}}(\mathrm{Cl})=0$ complex and the $\alpha$-carbon of the substrate. It is noteworthy that $(j)$, in the presence of chloride and water, can dissociate barrierless into (a) and the $\beta$-chlorohydrin (Figure S6).

The influence of the protein on this reactivity was then evaluated through the introduction of five amino acids close to the ruthenium complex. No significative changes were observed in terms of energy barriers. Conversely, some intermediate species were found to be conflicting with the presence of Trp398, which helps to discriminate between reaction pathways by controlling the orientation of the substrate and, therefore, the kinetics of the reaction. Thermodynamic energies favor an epoxide as the major species in most of the computed cases, whereas the kinetic $\beta$-chlorohydrin results from an attack on the substrate $C \alpha$, whereby the chlorine is the closest to the $C \beta$ radical carbon. Moreover, the presence of Trp398 helps to destabilize the enzyme-substrate complex, leading to catalysis. This aspect reveals that our system possesses allmost of the characteristics of an enzyme, i.e. a control of the substrate binding and orientation in an active site (see Figures S7 and S8 for a comprehensive point of view). This role adds to the promotion of the starting Ru2 species, as the hydrophobicity and the neutral charge of the protein environment affect the lability of the $t \mathrm{CO}$.

The calculations have shed light on the important energy barriers for most of the reaction pathways based on Ru1/2 studied here. For example, the activation of PIDA seems unrealistic unless we consider a spin crossover during the process. This outcome is related to the stability difference between the $\mathrm{Ru}(\mathrm{II})$ starting complex and the $\mathrm{Ru}(\mathrm{IV})=0$ oxidative species, the former being $\mathrm{S}=0$ and the latter $\mathrm{S}=1$. This difference is also present in the second set of calculations for the reactivity of $\mathrm{Ru}^{\mathrm{IV}}(\mathrm{Cl})=\mathrm{O}$ with the alkene substrate. There are then two ways to depict the dynamics of the reactions: one considering the whole process from PIDA activation to product release. In this case the reaction is driven by the large exothermic final step, and can be considered to occur at constant spin $\mathrm{S}=0$. An alternative consists 
of two spin crossovers $(S=0$ to $S=1$ and then $S=1$ to $S=0$ ) during the two main reactions. In this case, the energy barriers for all transformations will stay below $21 \mathrm{kcal} \mathrm{mol}^{-1}(21.0$ for the activation of PIDA, 12.8 and $7.5 \mathrm{kcal} \mathrm{mol}^{-1}$ for the oxygen transfer reactions). The second spin flip has also been proposed for iron oxene for $\mathrm{OAT}^{32}$ and recently for a $\mathrm{Ru}(\mathrm{IV})=\mathrm{O}$ species ${ }^{27}$ The latter example displayed the same free energy profiles as a function of spin states as the ones in our study but for the epoxidation of styrene. Here, in the case of MOS, the two-step process in the $\mathrm{S}=1$ state consists of formation of a Ru$\mathrm{O}-\mathrm{C} \beta$ bonded intermediate with a radical on $\mathrm{C} \alpha$, followed by the closing of the epoxide ring. The second step was calculated with a $24.5 \mathrm{kcal} \mathrm{mol}^{-1}$ barrier, too high to be realistic. The proposed spin crossover at this stage makes this step more feasible. As we cannot discriminate between the two processes, we can concentrate our effort, rather, on conciliating calculated reactivity and the different selectivities observed experimentally.

In summary, we have deciphered the reaction mechanism keeping in mind the selectivities observed. All the calculations are in line with the experimental observations. First, the thermodynamics may explain the difference in chemoselectivity between the two substrates. In the case of MOS, the formation of the chlorohydrin is too costly in energy compared to the epoxide formation. With BMS, access to both products is possible but the chlorohydrin is preferred $\left(\Delta \mathrm{E} \pm 17 \mathrm{kcal} \mathrm{mol}^{-1}\right.$ considering the spin state). Second, the regioselectivity for the chlorohydrin formation is explained by the radical character of the reaction. The slightly negative partial charge calculated for the double bonded oxygen atom in $\mathrm{Ru}^{\mathrm{IV}}(\mathrm{Cl})=\mathrm{O}$ precludes any electrophilic addition on alkenes. The radical attack of the $\mathrm{Ru}^{\mathrm{IV}}(\mathrm{Cl})=\mathrm{O}$ on the $\mathrm{C} \alpha$ of the aryl alkene double bond forms a Ru-O-C $\alpha$ bonded intermediate, $(\mathbf{m})$ or $(\mathbf{f})$ for BMS and MOS, respectively. This $\mathrm{Ru}(\mathrm{III})$ intermediate has a free radical character on $\mathrm{C} \beta$ (Table S5) that may potentially rotate along the $C \alpha-C \beta$ bond before the chlorine atom insertion or the epoxide ring formation. In the case of BMS, two structures of the chlorinated product have been modelled depending upon the spin state considered $((\mathbf{j})$ and $(\mathbf{n})$ for $S=0$ and $S=1$, respectively), revealing the direct insertion of the chlorine ligand from the ruthenium into the radical substrate. They differ only by the breaking of the $\mathrm{Ru}-\mathrm{Cl}$ bond. Their existence, in addition to the radical character of the reaction, should exclude the pathway implicating the insertion of a chloride anion from the buffer. Finally, in terms of diastereoselectivity, the $\mathrm{S}=0$ pathway does not fit the $73 \%$ diastereomeric excess obtained for the BMS oxidation that should be $100 \%$ if the oxygen and chlorine atoms were both inserted in a concerted way. Then, it is assumed that the $S=1$ pathway should be privileged in this case.

A plausible reaction mechanism is displayed in Figure 10 based on the common intermediate $\operatorname{Ru}^{\mathrm{IV}}(\mathrm{Cl})=\mathrm{O}$, as determined by the $\mathrm{QM}$ calculations. The selectivity between hydroxychlorination and epoxidation is driven by a competition between a thermodynamic and a kinetic pathway. In the case of MOS, the reaction follows a thermodynamic pathway, passing by the lowest energy barriers and the 
more stable intermediate, a C $\alpha$ radical stabilized by the methoxyphenyl substituent. This stabilization allows the reorganization necessary to the formation of the epoxide from the intermediate. In the case of BMS, the reaction follows the kinetic pathway passing by an attack on the less-hindered C $\alpha$ atom leading to an unstable $C \beta$ radical that reacts rapidly with the near chlorine atom. In both cases, the presence of a radical intermediate allows rotation along the $C \alpha-C \beta$ bond (black arrows in Figure 10) precluding the obtaining of any ee. At the end, the starting $\mathrm{Ru}(\mathrm{II})$ is formed again, confirmed by spin and NPA charge, after the coordination of a chloride, if necessary, and a water molecule to start a new cycle.

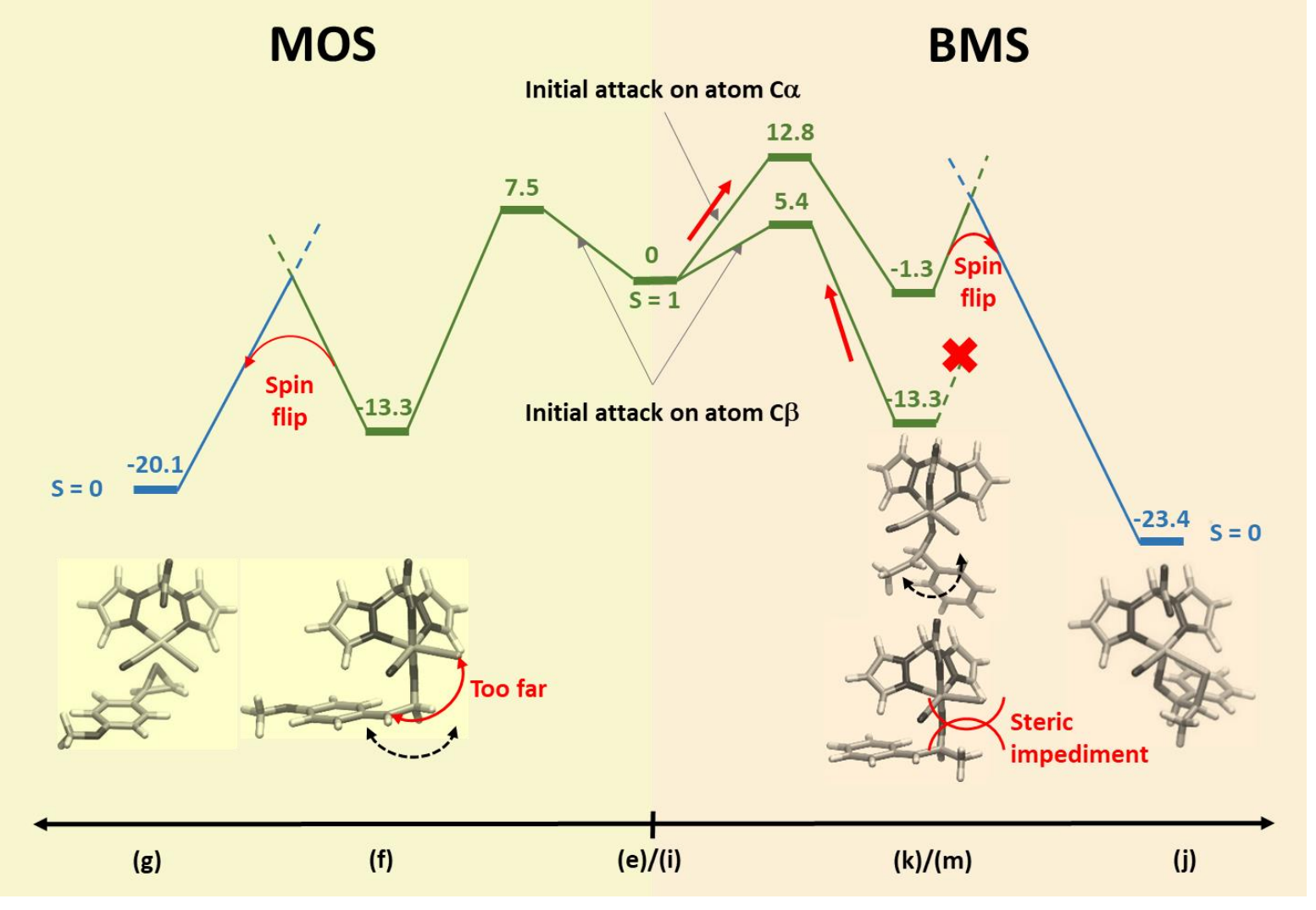

Figure 10. Comparison between MOS and BMS reactivity.

\section{Conclusion}

The design of new artificial enzymes is of great interest for abiotic chemical reactions. In this study, thanks to $x$-ray crystallographic data and combined experimental and computational studies, we have tried to clarify the impact of the insertion of a $\mathrm{Ru}(\mathrm{II})$ complex into a protein cavity in remarkable abiotic oxidation catalysis conditions. While a full $\mathrm{QM} / \mathrm{MM}$ study was unreachable, the $\mathrm{QM}$ evaluation of the complex alone and the experimental results helped us to define reasonable reaction pathways. We were able to propose a mechanism, revealing the different reaction pathways between two close substrates. The full reaction pathways were examined, revealing for the first time 
a reasonable route for $\mathrm{Ru}^{\mathrm{IV}}=\mathrm{O}$ formation from a hypervalent-iodine-based oxidant. During the calculations, the question of the spin transitions of the ruthenium at the two modelled stages of the whole process was not settled. The role of the protein environment was highlighted, and it was demonstrated that the selectivity of the artificial enzyme is due to i) the promotion of the starting oxidizing species via the exchange of a CO ligand, and ii) the control of the substrate orientation on the intermediate structures, formed after the $\mathrm{Ru}^{\mathrm{IV}}=\mathrm{O}$ attack: when $\mathrm{C} \alpha$ attack is preferred, chlorohydrin is formed while attack on $C \beta$ leads to an epoxide. This work contributes to the promotion of artificial metalloenzymes as alternative to natural enzymes for the purpose of non-natural reactions.

\section{Experimental part}

\section{Hybrid preparation}

EcNikA was purified and EcNikA-Ru1 was prepared as previously described. ${ }^{4}$ The synthesis of EcNikA$\operatorname{Mg}($ EDTA) was performed by incubating $500 \mu \mathrm{L}$ of a $500 \mu \mathrm{M}$ protein solution with a 2 -fold excess of $\mathrm{Mg}(\mathrm{EDTA})$ in $40 \mathrm{mM}$ Tris- $\mathrm{HCl} \mathrm{pH} 7.5$ at $4^{\circ} \mathrm{C}$ overnight. Complex excess was removed using a desalting column (PD10), followed by concentration on a centricon filter with a $30 \mathrm{kDa}$ cut-off (4 cycles) which led to the separation of the protein-complex hybrid from the complex-free solution.

\section{Catalytic standard procedure}

$10 \mu \mathrm{L}$ of a $496 \mu \mathrm{M}$ EcNikA solution $(5 \mathrm{nmol})$ in a Tris. $\mathrm{HCl}$ buffer $40 \mathrm{mM} \mathrm{pH} 7.0$ were mixed with $30 \mu \mathrm{L}$ of a $8.10^{-4} \mathrm{M}$ complex solution ( $25 \mathrm{nmol}$ ) for 30 minutes. Then, $88 \mu \mathrm{L}$ of HEPES buffer $10 \mathrm{mM} \mathrm{pH} \mathrm{7.0,6}$ $\mu \mathrm{L}$ of a $0.41 \mathrm{M}$ solution of 4 -methoxystyrene $(2.46 \mu \mathrm{mol})$ and $1 \mathrm{mg}$ of iodobenzene diacetate ( $3 \mu \mathrm{mol})$ were added. The reaction was performed at room temperature for 10 minutes, and the reaction mixture was extracted with AcOEt $(200 \mu \mathrm{L})$. The organic phase was analyzed by GC/MS

\section{Theoretical calculations methods}

Oxidation of trans- $\beta$-methyl- and 4-methoxy-styrene were studied using computational quantum chemistry with the Gaussian g09 program. ${ }^{25}$ The DFT method and B3LYP functional ${ }^{9}$ with the def2-SVP split valence polarization basis set ${ }^{10}$ and empirical dispersion correction (GD3BJ) $)^{31}$ were used by default for most calculations. The Polarizable Continuum Model (PCM) was used to describe the solvating water. All the calculations were done in open shell mode (UB3LYP) but the Gaussian singlet state wave functions and / or optimization algorithms seem to always result in strict 0.0 spin contributions for all atoms. To enforce singlet state open shell calculations with non-zero spins on all atoms, we optimized 
singlet state geometries with the corresponding triplet state wave function as initial guess (Guess=Read). Stability of the wave functions has been carefully checked in each case.

Most calculations have been reproduced in the absence of the dispersion correction term and relative energies are similar to those presented in the text.

Calculations were also checked by changing basis set and functional and compare the energy differences between singlet and triplet states for most optimized geometries and transitions states reported with the def2-SVP basis set. The meta-GGA M11-L dual-range exchange functional ${ }^{33}$ was used with the triple zeta Def2TZVP basis set. ${ }^{10,34}$ Some variations are observed between the two methods but the conclusions are identical.

Supporting information. Catalysis tables, $x$-rays structure refinement and statistics, computational details. This information is available free of charge on the ACS Publication website.

\section{Acknowledgement}

We thank the Agence Nationale pour la Recherche for grant (ANR-14-CE06-0005-01), and the CEA, CNRS and Univ. Grenoble-Alpes for their institutional support. This work has been partially supported by Labex ARCANE (ANR-11-LABEX-0003-1) and CBH-EUR-GS (ANR-17-EURE-0003).

\section{References}

(1) a) Anastas, P.; Eghbali, N. Green Chemistry: Principles and Practice. Chem. Soc. Rev. 2010, 39, 301-312; b) Sheldon, R. A. Fundamentals of Green Chemistry: Efficiency in Reaction Design. Chem. Soc. Rev. 2012, 41, 1437-1451.

(2) a) Lewis, J. C. Artificial Metalloenzymes and Metallopeptide Catalysts for Organic Synthesis. ACS Catal. 2013, 3, 2954-2975; b) Yu, F.; Cangelosi, V. M.; Zastrow, M. L.; Tegoni, M.; Plegaria, J. S.; Tebo, A. G.; Mocny, C. S.; Ruckthong, L.; Qayyum, H.; Pecoraro, V. L. Protein Design: Toward Functional Metalloenzymes. Chem. Rev. 2014, 114, 3495-3578; c) Marchi-Delapierre, C.; Rondot, L.; Cavazza, C.; Ménage, S. Oxidation Catalysis by Rationally Designed Artificial Metalloenzymes. Isr. J. Chem. 2015, 55, 61-75; d) Schwizer, F.; Okamoto, Y.; Heinisch, T.; Gu, Y.; Pellizzoni, M. M.; Lebrun, V.; Reuter, R.; Köhler, V.; Lewis, J. C.; Ward, T. R. Artificial Metalloenzymes: Reaction Scope and Optimization Strategies. Chem. Rev. 2018, 118, 142-231.

(3) a) Lu, Y. Biosynthethic Inorganic Chemistry. Angew. Chem. Int. Ed. 2006, 45, 5588-5601; b) Bornscheuer, U. T.; Huisman, G. W.; Kazlauskas, R. J.; Lutz, S.; Moore, J. C.; Robins, K. Engineering the Third Wave of Biocatalysis. Nature 2012, 485, 185-194; c) Drienovská, I.; Rioz-Martínez, A.; Draksharapu, A.; Roelfes, G. Novel Artificial Metalloenzymes by in Vivo Incorporation of Metal-Binding Unnatural Amino Acids. Chem. Sci. 2015, 6, 770-776; d) Dydio, P.; Key, H. M.; Nazarenko, A.; Rha, J. Y.E.; Seyedkazemi, V.; Clark, D. S.; Hartwig, J. F. An Artificial Metalloenzyme with the Kinetics of Native Enzymes. Science 2016, 354, 102-106; e) Prier, C. K.; Zhang, R. K.; Buller, A. R.; Brinkmann-Chen, S.; Arnold, F. H. Enantioselective, Intermolecular Benzylic C-H Amination Catalysed by an Engineered IronHaem Enzyme. Nat. Chem. 2017, 9, 629; f) Hammer, S. C.; Kubik, G.; Watkins, E.; Huang, S.; Minges, H.; Arnold, F. H. Anti-Markovnikov Alkene Oxidation by Metal-Oxo-Mediated Enzyme Catalysis. Science 
2017, 358, 215-218; g) Agostini, F.; Völler, J.-S.; Koksch, B.; Acevedo-Rocha, C. G.; Kubyshkin, V.; Budisa, N. Biocatalysis with Unnatural Amino Acids: Enzymology Meets Xenobiology. Angew. Chem. Int. Ed. 2017, 56, 9680-9703; h) Mayer, C.; Dulson, C.; Reddem, E.; Thunnissen, A.-M. W. H.; Roelfes, G. Directed Evolution of a Designer Enzyme Featuring an Unnatural Catalytic Amino Acid. Angew. Chem. Int. Ed. 2019, 58, 2083-2087.

(4) Lopez, S.; Rondot, L.; Cavazza, C.; lannello, M.; Boeri-Erba, E.; Burzlaff, N.; Strinitz, F.; JorgeRobin, A.; Marchi-Delapierre, C.; Menage, S. Efficient Conversion of Alkenes to Chlorohydrins by a RuBased Artificial Enzyme. Chem. Commun. 2017, 53, 3579-3582.

(5) a) Vaillancourt, F. H.; Yeh, E.; Vosburg, D. A.; O'Connor, S. E.; Walsh, C. T. Cryptic Chlorination by a Non-Haem Iron Enzyme During Cyclopropyl Amino Acid Biosynthesis. Nature 2005, 436, $1191-$ 1194; b) Vaillancourt, F. H.; Yin, J.; Walsh, C. T. Syrb2 in Syringomycin E Biosynthesis Is a Nonherne FeIi Alpha-Ketoglutarate- and O-2-Dependent Halogenase. PNAS 2005, 102, 10111-10116; c) Vaillancourt, F. H.; Yeh, E.; Vosburg, D. A.; Garneau-Tsodikova, S.; Walsh, C. T. Nature's Inventory of Halogenation Catalysts: Oxidative Strategies Predominate. Chem. Rev. 2006, 106, 3364-3378; d) Galonić, D. P.; Barr, E. W.; Walsh, C. T.; Bollinger Jr, J. M.; Krebs, C. Two Interconverting Fe(Iv) Intermediates in Aliphatic Chlorination by the Halogenase Cytc3. Nat. Chem. Biol. 2007, 3, 113; e) Khare, D.; Wang, B.; Gu, L.; Razelun, J.; Sherman, D. H.; Gerwick, W. H.; Håkansson, K.; Smith, J. L. Conformational Switch Triggered by A-Ketoglutarate in a Halogenase of Curacin a Biosynthesis. PNAS 2010, 107, 14099-14104; f) Pratter, S. M.; Light, K. M.; Solomon, E. I.; Straganz, G. D. The Role of Chloride in the Mechanism of $\mathrm{O} 2$ Activation at the Mononuclear Nonheme Fe(li) Center of the Halogenase Hctb. J. Am. Chem. Soc. 2014, 136, 9385-9395.

(6) Kohler, V.; Mao, J. C.; Heinisch, T.; Pordea, A.; Sardo, A.; Wilson, Y. M.; Knorr, L.; Creus, M.; Prost, J. C.; Schirmer, T.; Ward, T. R. Oso4 Center Dot Streptavidin: A Tunable Hybrid Catalyst for the Enantioselective Cis-Dihydroxylation of Olefins. Angew. Chem. Int. Ed. 2011, 50, 10863-10866.

(7) Tuerkoglu, G.; Tampier, S.; Strinitz, F.; Heinemann, F. W.; Huebner, E.; Burzlaff, N. Ruthenium Carbonyl Complexes Bearing Bis(Pyrazol-1-YI)Carboxylato Ligands. Organometallics 2012, 31, 21662174.

(8) a) Zygmunt, S. A.; Curtiss, L. A.; Iton, L. E.; Erhardt, M. K. Computational Studies of Water Adsorption in the Zeolite H-Zsm-5. J. Phys. Chem. 1996, 100, 6663-6671; b) Santos-Silva, T.; Mukhopadhyay, A.; Seixas, J. D.; Bernardes, G. J. L.; Romão, C. C.; Romão, M. J. Corm-3 Reactivity toward Proteins: The Crystal Structure of a Ru(li) Dicarbonyl-Lysozyme Complex. J. Am. Chem. Soc. 2011, 133, 1192-1195; c) Santos, M. F. A.; Seixas, J. D.; Coelho, A. C.; Mukhopadhyay, A.; Reis, P. M.; Romão, M. J.; Romão, C. C.; Santos-Silva, T. New Insights into the Chemistry of Fac-[Ru(Co)3]2 + Fragments in Biologically Relevant Conditions: The Co Releasing Activity of [Ru(Co)3cl2(1,3-Thiazole)], and the X-Ray Crystal Structure of Its Adduct with Lysozyme. J. Inorg. Biochem. 2012, 117, 285-291.

(9) a) Becke, A. D. Density-Functional Exchange-Energy Approximation with Correct Asymptotic Behavior. Phys. Rev. A 1988, 38, 3098-3100; b) Lee, C.; Yang, W.; Parr, R. G. Development of the ColleSalvetti Correlation-Energy Formula into a Functional of the Electron Density. Phys. Rev. B 1988, 37, 785-789; c) Becke, A. D. Density-Functional Thermochemistry. lii. The Role of Exact Exchange. J. Chem. Phys. 1993, 98, 5648-5652.

(10) Weigend, F.; Ahlrichs, R. Balanced Basis Sets of Split Valence, Triple Zeta Valence and Quadruple Zeta Valence Quality for H to Rn: Design and Assessment of Accuracy. Phys. Chem. Chem. Phys. 2005, 7, 3297-3305. 
(11) Cherrier, M. V.; Girgenti, E.; Amara, P.; Iannello, M.; Marchi-Delapierre, C.; Fontecilla-Camps, J. C.; Menage, S.; Cavazza, C. The Structure of the Periplasmic Nickel-Binding Protein Nika Provides Insights for Artificial Metalloenzyme Design. J. Biol. Inorg. Chem. 2012, 17, 817-829.

(12) Nasrallah, A.; Grelier, G.; Lapuh, M. I.; Duran, F. J.; Darses, B.; Dauban, P. Dirhodium(li)Mediated Alkene Epoxidation with lodine(lii) Oxidants. Eur. J. Org. Chem. 2018, 5836-5842.

(13) Cherrier, M. V.; Martin, L.; Cavazza, C.; Jacquamet, L.; Lemaire, D.; Gaillard, J.; FontecillaCamps, J. C. Crystallographic and Spectroscopic Evidence for High Affinity Binding of Feedta(H2O)(-) to the Periplasmic Nickel Transporter Nika. J. Am. Chem. Soc. 2005, 127, 10075-10082.

(14) Sawyer, D. T.; Paulsen, P. J. Properties and Infrared Spectra of Ethylenediaminetetraacetic Acid Complexes. I. Alkaline Earth Chelates1. J. Am. Chem. Soc. 1958, 80, 1597-1600.

(15) a) Yusubov, M. S.; Drygunova, L. A.; Zhdankin, V. V. 4,4'-Bis(Dichloroiodo)Biphenyl and 3(Dichloroiodo)Benzoic Acid: New Recyclable Hypervalent lodine Reagents for Vicinal Halomethoxylation of Unsaturated Compounds. Synthesis 2004, 2004, 2289-2292; b) Zhdankin, V. V.; Stang, P. J. Chemistry of Polyvalent lodine. Chem. Rev. 2008, 108, 5299-5358.

(16) Coffey, K. E.; Moreira, R.; Abbas, F. Z.; Murphy, G. K. Synthesis of 3,3-Dichloroindolin-2-Ones from Isatin-3-Hydrazones and (Dichloroiodo)Benzene. Org. Biomol. Chem. 2015, 13, 682-685.

(17) a) Ochiai, M.; Miyamoto, K.; Shiro, M.; Ozawa, T.; Yamaguchi, K. Isolation, Characterization, and Reaction of Activated lodosylbenzene Monomer Hydroxy(Phenyl)lodonium lon with Hypervalent Bonding: Supramolecular Complex Phi+Oh.18-Crown-6 with Secondary I... Interactions. J. Am. Chem. Soc. 2003, 125, 13006-13007; b) Ochiai, M. Intermolecular Hypervalent I(lii)...O Interactions: A New Driving Force for Complexation of Crown Ethers. Coord. Chem. Rev. 2006, 250, 2771; c) Yusubov, M. S.; Nemykin, V. N.; Zhdankin, V. V. Transition Metal-Mediated Oxidations Utilizing Monomeric lodosyland lodylarene Species. Tetrahedron 2010, 66, 5745-5752.

(18) a) Li, Z.; Tang, Z. H.; Hu, X. X.; Xia, C. G. Insight into the Mechanism of Oxidative Kinetic Resolution of Racemic Secondary Alcohols by Using Manganese(lii)(Salen) Complexes as Catalysts. Chem. Eur. J. 2005, 11, 1210-1216; b) Yoshimura, A.; Zhdankin, V. V. Advances in Synthetic Applications of Hypervalent lodine Compounds. Chem. Rev. 2016, 116, 3328-3435; c) Ishizuka, T.; Kotani, H.; Kojima, T. Characteristics and Reactivity of Ruthenium-Oxo Complexes. Dalton Trans. 2016, 45, 16727-16750; d) Aguirre, P.; Sariego, R.; Moya, S. A. Ruthenium (li) Complexes in Catalytic Oxidation. J. Coord. Chem. 2001, 54, 401-413; e) Di Giovanni, C.; Vaquer, L.; Sala, X.; Benet-Buchholz, J.; Llobet, A. New Dinuclear Ruthenium Complexes: Structure and Oxidative Catalysis. Inorg. Chem. 2013, 52, 4335-4345; f) Aguiló, J.; Francàs, L.; Bofill, R.; Gil-Sepulcre, M.; García-Antón, J.; Poater, A.; Llobet, A.; Escriche, L.; Meyer, F.; Sala, X. Powerful Bis-Facially Pyrazolate-Bridged Dinuclear Ruthenium Epoxidation Catalyst. Inorg. Chem. 2015, 54, 6782-6791.

(19) Blasiak, L. C.; Vaillancourt, F. H.; Walsh, C. T.; Drennan, C. L. Crystal Structure of the Non-Haem Iron Halogenase Syrb2 in Syringomycin Biosynthesis. Nature 2006, 440, 368-371.

(20) a) Wagenknecht, H.-A.; Woggon, W.-D. New Active-Site Analogues of ChloraperoxidaseSyntheses and Catalytic Reactions. Angew. Chem., Int. Ed. Engl. 1997, 36, 390-392; b) Stone, K. L.; Behan, R. K.; Green, M. T. X-Ray Absorption Spectroscopy of Chloroperoxidase Compound I: Insight into the Reactive Intermediate of P450 Chemistry. PNAS 2005, 102, 16563-16565; c) Rohde, J.-U.; Bukowski, M. R.; Que Jr, L. Functional Models for Mononuclear Nonheme Iron Enzymes. Curr. Opin. Chem. Biol. 2003, 7, 674-682; d) Chow, T. W. S.; Wong, E. L. M.; Guo, Z.; Liu, Y. G.; Huang, J. S.; Che, C. M. CisDihydroxylation of Alkenes with Oxone Catalyzed by Iron Complexes of a Macrocyclic Tetraaza Ligand 
and Reaction Mechanism by Esi-Ms Spectrometry and Dft Calculations. J. Am. Chem. Soc. 2010, 132, 13229-13239; e) Bruijnincx, P. C. A.; Buurmans, I. L. C.; Gosiewska, S.; Moelands, M. A. H.; Lutz, M.; Spek, A. L.; van Koten, G.; Gebbink, R. Iron(li) Complexes with Bio-Inspired N,N,O Ligands as Oxidation Catalysts: Olefin Epoxidation and Cis-Dihydroxylation. Chemistry-a European Journal 2008, 14, 1228 1237.

(21) a) Fukuzumi, S.; Kojima, T.; Lee, Y.-M.; Nam, W. High-Valent Metal-Oxo Complexes Generated in Catalytic Oxidation Reactions Using Water as an Oxygen Source. Coord. Chem. Rev. 2017, 333, 4456; b) Nam, W. High-Valent Iron(IV)-Oxo Complexes of Heme and Non-Heme Ligands in Oxygenation Reactions. Acc. Chem. Res. 2007, 40, 522-531; c) Que, L. The Road to Non-Heme Oxoferryls and Beyond. Acc. Chem. Res. 2007, 40, 493-500; d) Lv, Z.; Zheng, W.; Chen, Z.; Tang, Z.; Mo, W.; Yin, G. Synergistic Oxygen Atom Transfer by Ruthenium Complexes with Non-Redox Metal Ions. Dalton Trans. 2016, 45, 11369-11383.

(22) Provins, L.; Murahashi, S.-I. Oxidation of Olefins Catalyzed by New Binaphthyl-Ruthenium(lii) Complexes. ARKIVOC 2007, 107-120.

(23) Yusubov, M. S.; Chi, K.-W.; Park, J. Y.; Karimov, R.; Zhdankin, V. V. Highly Efficient Rucl3Catalyzed Disproportionation of (Diacetoxyiodo)Benzene to lodylbenzene and lodobenzene; Leading to the Efficient Oxidation of Alcohols to Carbonyl Compounds. Tetrahedron Lett. 2006, 47, 6305-6308.

(24) Pagliaro, M.; Campestrini, S.; Ciriminna, R. Ru-Based Oxidation Catalysis. Chem. Soc. Rev. 2005, $34,837-845$.

(25) Frisch, M. J.; Trucks, G. W.; Schlegel, H. B.; Scuseria, G. E.; Robb, M. A.; Cheeseman, J. R.; Montgomery, J., J. A.; ; Vreven, T.; Kudin, K. N.; Burant, J. C.; Millam, J. M.; Lyengar, S. S.; Tomasi, J.; Barone, V.; Mennucci, B.; Cossi, M.; Scalmani, G.; Rega, N.; Petersson, G. A.; Nakatsuji, H.; Hada, M.; Ehara, M.; Toyota, K.; Fukuda, R.; Hasegawa, J.; Ishida, M.; Nakajima, T.; Honda, Y.; Kitao, O.; Nakai, H.; Klene, M.; Li, X.; Knox, J. E.; Hratchian, H. P.; Cross, J. B.; Bakken, V.; Adamo, C.; Jaramillo, J.; Gomperts, R.; Stratmann, R. E.; Yazyev, O.; Austin, A. J.; Cammi, R.; Pomelli, C.; Ochterski, J. W.; Ayala, P. Y.; Morokuma, K.; Voth, G. A.; Salvador, P.; Dannenberg, J. J.; Zakrzewski, V. G.; Dapprich, S.; Daniels, A. D.; Strain, M. C.; Farkas, O.; Malick, D. K.; Rabuck, A. D.; Raghavachari, K.; Foresman, J. B.; Ortiz, J. V.; Cui, Q.; Baboul, A. G.; Clifford, S.; Cioslowski, J.; Stefanov, B. B.; Liu, G.; Liashenko, A.; Piskorz, P.; Komaromi, I.; Martin, R. L.; Fox, D. J.; Keith, T.; Al-Laham, M. A.; Peng, C. Y.; Nanayakkara, A.; Challacombe, M.; Gill, P. M. W.; Johnson, B.; Chen, W.; Wong, M. W.; Gonzalez, C.; Pople, J. A. Gaussian 03, Revision C.02; Gaussian, Inc., Wallingford CT, 2004.

(26) Mennucci, B.; Cammi, R.; Tomasi, J. Excited States and Solvatochromic Shifts within a Nonequilibrium Solvation Approach: A New Formulation of the Integral Equation Formalism Method at the Self-Consistent Field, Configuration Interaction, and Multiconfiguration Self-Consistent Field Level. The Journal of Chemical Physics 1998, 109, 2798-2807.

(27) Dhuri, S. N.; Cho, K.-B.; Lee, Y.-M.; Shin, S. Y.; Kim, J. H.; Mandal, D.; Shaik, S.; Nam, W. Interplay of Experiment and Theory in Elucidating Mechanisms of Oxidation Reactions by a Nonheme Ruivo Complex. J. Am. Chem. Soc. 2015, 137, 8623-8632.

(28) Lennartson, A.; McKenzie, C. J. An Iron(lii) lodosylbenzene Complex: A Masked Non-Heme Fevo. Angew. Chem. Int. Ed. 2012, 51, 6767-6770.

(29) a) Shaik, S.; de Visser, S. P.; Ogliaro, F.; Schwarz, H.; Schröder, D. Two-State Reactivity Mechanisms of Hydroxylation and Epoxidation by Cytochrome P-450 Revealed by Theory. Curr. Opin. Chem. Biol. 2002, 6, 556-567; b) Linde, C.; Koliaï, N.; Norrby, P.-O.; Åkermark, B. Experimental Evidence 
for Multiple Oxidation Pathways in the (Salen)Mn-Catalyzed Epoxidation of Alkenes. Chem. Eur. J. 2002, 8, 2568-2573; c) Hess, J. S.; Leelasubcharoen, S.; Rheingold, A. L.; Doren, D. J.; Theopold, K. H. Spin Surface Crossing in Chromium-Mediated Olefin Epoxidation with O2. J. Am. Chem. Soc. 2002, 124, 24542455; d) Guo, M.; Lee, Y.-M.; Seo, M. S.; Kwon, Y.-J.; Li, X.-X.; Ohta, T.; Kim, W.-S.; Sarangi, R.; Fukuzumi, S.; Nam, W. Mn(lii)-lodosylarene Porphyrins as an Active Oxidant in Oxidation Reactions: Synthesis, Characterization, and Reactivity Studies. Inorg. Chem. 2018, 57, 10232-10240.

(30) Yang, Y.; Diederich, F.; Valentine, J. S. Lewis Acidic Catalysts for Olefin Epoxidation by lodosylbenzene. J. Am. Chem. Soc. 1991, 113, 7195-7205.

(31) Grimme, S. Semiempirical Gga-Type Density Functional Constructed with a Long-Range Dispersion Correction. J. Comput. Chem. 2006, 27, 1787-1799.

(32) a) Usharani, D.; Janardanan, D.; Li, C.; Shaik, S. A Theory for Bioinorganic Chemical Reactivity of Oxometal Complexes and Analogous Oxidants: The Exchange and Orbital-Selection Rules. Acc. Chem. Res. 2013, 46, 471-482; b) Kwon, Y. H.; Mai, B. K.; Lee, Y.-M.; Dhuri, S. N.; Mandal, D.; Cho, K.-B.; Kim, Y.; Shaik, S.; Nam, W. Determination of Spin Inversion Probability, H-Tunneling Correction, and Regioselectivity in the Two-State Reactivity of Nonheme Iron(Iv)-Oxo Complexes. J. Phys. Chem. Lett. 2015, 6, 1472-1476.

(33) Peverati, R.; Truhlar, D. G. M11-L: A Local Density Functional That Provides Improved Accuracy for Electronic Structure Calculations in Chemistry and Physics. J. Phys. Chem. Lett. 2012, 3, 117-124.

(34) Weigend, F. Accurate Coulomb-Fitting Basis Sets for H to Rn. Phys. Chem. Chem. Phys. 2006, 8, 1057-1065. 
Graphic for Table Of Content

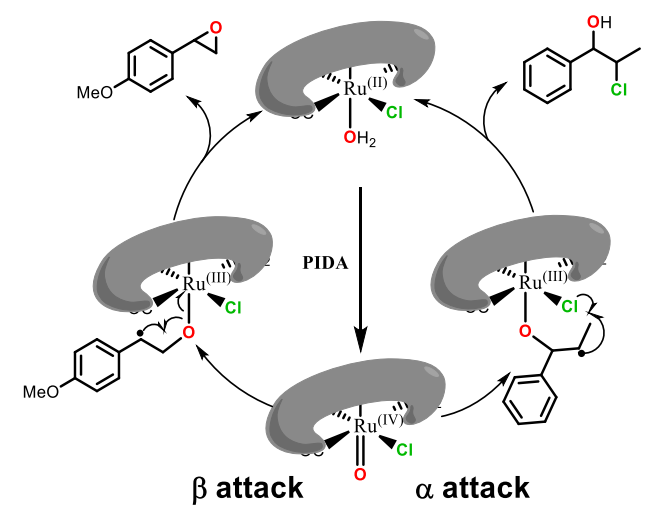

